\title{
Los manuales de salud en la Nueva Granada (1760-1810) ¿El remedio al pie de la letra?
}

\author{
Adriana María Alzate Echeverri \\ Universidad del Rosario, Bogotá \\ alzate_adriana@yahoo.fr
}

\section{Resumen $^{1}$}

El artículo muestra el importante lugar que progresivamente van tomando los manuales de salud entre las lecturas ilustradas durante los cincuenta años que precedieron a la Independencia en la Nueva Granada y los usos de los que fueron objeto en este territorio. Se pone en evidencia su empleó para nutrir las argumentaciones de las autoridades y de la élite neogranadina en pro de la instauración de ciertas medidas de salud pública; para remediar las dificultades producidas por la falta de médicos -o por el alto costo de sus honorarios, cuando los había-; para identificar las virtudes de algunas plantas medicinales existentes en estas tierras y ponerlas así al servicio de los enfermos, y para respaldar formas de automedicación entre los sectores ilustrados de la sociedad.

Palabras clave: HISTORIA DE LA MEDICINA, MANUALES DE SALUD, NUEVA GRANADA, SIGLO XVIII.

\begin{abstract}
This article shows how health manuals slowly gained importance among thoughtful readers in the fifty years prior to independence in New Granada and the use to which they were put in this territory. The text evidences their use in arguments made by public authorities and the elites of New Granada in favor of implementing certain public health measures, to solve the difficulties posed by a lack of doctors-or their high cost, when they were available-to identifysome of the medicinal plants locally available and use them to treat the sick, and to support certain forms of self-medication among the illustrated elites.

Key words: HISTORY OF MEDICINE, MEDICINE HANDBOOKS, NUEVA GRANADA, $18^{\mathrm{TH}}$ CENTURY.

\footnotetext{
${ }^{1}$ Este artículo forma parte de la tesis de doctorado titulada "Saleté et ordre. Réformes sanitaires et société dans la vice-royauté espagnole de la Nouvelle-Grenade 1760-1810", sustentada en octubre de 2004 en la Universidad de París 1 (Panthéon-Sorbonne). Una parte de este trabajo de tesis contó con la colaboración financiera de la Fundación para la Promoción de la Ciencia y la Tecnología del Banco de la Republica de Colombia.
} 
Las publicaciones divulgativas relacionadas con la conservación y restablecimiento de la salud conocen, tanto en el Viejo como en el Nuevo Mundo, un auge importante durante la segunda mitad del siglo XVIII. Este fenómeno se inscribe en el amplio contexto de una nueva valoración de la vida humana, de la preocupación por el crecimiento y la salud de las poblaciones como recurso esencial para los gobiernos y de la concepción de la salud corporal como un elemento fundamental para alcanzar la felicidad y la prosperidad social. Esta situación debe, asimismo, relacionarse con el peso que la medicina comienza a tomar durante este siglo, con algunas condiciones sociales, políticas y culturales -como el crecimiento demográfico del Occidente europeo y la urgencia de controlar la población en aumento mediante mecanismos de poder más adaptados- o con la consideración de las enfermedades como fenómeno político y económico, y es un auge que obedece también al carácter pedagógico que animaba al pensamiento ilustrado ${ }^{2}$.

En cuanto a España y sus colonias, debe igualmente tenerse en cuenta que, a partir de mediados del siglo XVIII, tanto los ideales ilustrados como algunos de los intereses políticos y económicos de la Casa de Borbón condujeron al establecimiento de una serie de reformas económicas, sociales y culturales tanto en la metrópoli como en sus colonias americanas. En este contexto, se intentó establecer una "política de salud" que pretendía sostener ese conjunto de transformaciones y perseguía, entre otros objetivos, el establecimiento de medidas para luchar contra las epidemias ${ }^{3}$, la organización y el saneamiento del espacio urbano, el desplazamiento de los cementerios fuera de las ciudades, la reestructuración de la institución hospitalaria y la renovación de los estudios médicos.

Hubo otro ámbito importante, que es el objeto de este artículo, relacionado con la traducción y puesta en circulación en España y sus colonias de cierto tipo de libros sobre la salud. Estos libros nutrieron las argumentaciones de las autoridades españolas y de la élite ilustrada neogranadina en pro de la instauración de ciertas medidas de salud pública y se emplearon para remediar las dificultades producidas por la falta de médicos en este territorio o por el alto costo de sus honorarios, cuando los había; para identificar las virtudes y los usos de algunas plantas

\footnotetext{
${ }^{2}$ Véase Othmar Keel, L'avènement de la médecine clinique moderne en Europe, 17501815. Politiques, institutions et savoirs (Montréal: Les Presses Universitaires de MontréalGerg Editeur, 2001), 26. Michel Foucault, "La politique de santé au XVIII siècle", en Michel Foucault. Dits et Ecrits, t. 2 (París: Gallimard, 2001), 14.

${ }^{3}$ Para el tema de las epidemias de viruela en la Nueva Granada, remítase a Renán Silva, Las epidemias de la viruela de 1782 y 1802 en la Nueva Granada (Cali: Universidad del Valle, 1992); Marcelo Frías Núñez, Enfermedad y sociedad en la crisis colonial del Antiguo Régimen. Nueva Granada en el tránsito del siglo XVIII al XIX: las epidemias de viruelas (Madrid: CSIC, 1992); Ana Luz Rodríguez, Cofradías, capellanías, epidemias y funerales (Bogotá: Banco de la República, 1999).
} 
medicinales existentes en el virreinato y ponerlas así al servicio de los enfermos, y para respaldar formas de automedicación entre sectores ilustrados de la sociedad neogranadina, conformados por algunos miembros de la nobleza urbana, del clero, funcionarios reales, militares, abogados, profesores y estudiantes universitarios, $\mathrm{y}$ algunos comerciantes.

Esta política de salud pública se dibuja en el siglo XVIII, en grados, niveles e intensidades diferentes, en todos los países de Europa, y tuvo como una de sus principales metas el privilegio de la higiene y el funcionamiento de la medicina como instancia de control social. En este sentido, la antigua noción de "régimen", entendida a la vez como regla de vida y como forma de medicina preventiva, tiende a extenderse ${ }^{4}$. Con la aplicación de esta noción de régimen colectivo se buscaban tres fines esenciales: la desaparición de las epidemias, el descenso de las tasas de mortalidad y la extension de la duración media de vida.

Los manuales de salud que aquí se estudiarán aparecen citados en los dictámenes y textos de diferente índole escritos por diversos funcionarios y por médicos o sacerdotes, bien fuera a petición del virrey, de las autoridades locales o por iniciativa individual, para resolver problemas de salud pública. Se encuentran también mencionados en la correspondencia sostenida entre varios de los miembros de esta élite, la cual pone de manifiesto la existencia de una prístina red científica en la Nueva Granada; la abundancia de los intercambios epistolares es una de las muestras de la intensa circulación de saberes que se produce desde finales del siglo XVIII ${ }^{6}$. Asimismo, diferentes manuales de salud se hallan referenciados en los artículos publicados sobre temas de salud en la prensa neogranadina, la cual no solo llevó a cabo una amplia obra divulgativa del pensamiento europeo de entonces en la Nueva Granada, sino que sacó a la luz elaboraciones escritas por ilustrados sobre los problemas de salud más acuciantes de este territorio. Por último, los inventarios de algunas de las bibliotecas de los ilustrados confirman la presencia constante de varias de estas obras.

\section{Prácticas de lectura en la Nueva Granada}

\footnotetext{
${ }^{4}$ Según la medicina hipocrática, el régimen tenía un rol preventivo y curativo. El régimen no comprendía solo la actitud de moderación de los alimentos y de las bebidas que consumían los individuos, sino también el sueño, la vigilia, el ejercicio físico o la actividad sexual. Jacques Jouanna y Caroline Magdelaine, "Présentation", en L'art de la médecine, Hippocrate (París: GF Flammarion, 1999), 27.

${ }_{6}^{5}$ Michel Foucault, "La politique de santé au XVIIIe siècle", 19.

${ }^{6}$ A través de la correspondencia también se realiza un comercio de objetos de diferente naturaleza: traducciones de fragmentos de libros, comentarios de lecturas, copias literales de textos, referencias de artículos enciclopédicos, recetas e incluso recortes de periódicos o de gacetas, y aun ejemplares de plantas, semillas, etc.
} 
Durante la segunda mitad del siglo XVIII, las prácticas de lectura en la Nueva Granada sufrieron algunas modificaciones significativas. Estos cambios, que se presentan solo en una pequeña élite cultural, están orientados esencialmente hacia una nueva relación con el impreso, que se traducirá en varios aspectos: la creación de periódicos locales; la fundación de asociaciones de lectura (tertulias) en los medios urbanos ${ }^{7}$; la circulación más intensa, el intercambio constante y la lectura colectiva de libros; la aparición de nuevas formas de lectura en el campo; el interés permanente por adquirir nuevos libros, y el progresivo valor otorgado a la lectura de gacetas ${ }^{8}$.

Las tertulias constituyen un tipo de sociabilidad moderna que remite a un espacio cultural unido por redes de intercambios epistolares y humanos importantes. Se trata de un medio que posee una sensibilidad común, de un grupo que realiza las mismas lecturas y las mismas prácticas societariasy que estima lo útil, con fe creciente en el progreso y en la felicidad futura. Las tertulias sitúan en el centro de sus actividades la discusión, la reflexión, la elaboración y la difusión de conocimientos y de "novedades" y la lectura de libros, gacetas o manuscritos. Sus reuniones y sus producciones enrutan el proceso de circulación extendida de ciertas referencias culturales y de "uniformización de las prácticas", y aportan un terreno fértil a la reflexión crítica".

En la Nueva Granada, las tertulias fueron de los sitios más frecuentados por los estudiantes universitarios, especialmente en Santafé. Se llevaban a cabo en las habitaciones estudiantiles de los centros de enseñanza capitalinos, en algunas

\footnotetext{
${ }^{7}$ A finales del XVIII y principios del siglo XIX, las tertulias y las sociedades económicas de amigos del país fueron las formas de sociabilidad moderna más importantes tanto en España como en la América española; tales sociedades se encuentran esencialmente en el mundo de las élites y publican varios de los nuevos diarios americanos: El Mercurio Peruano, la Gaceta de Guatemala o El Telégrafo Mercantil de Buenos Aires, publicaciones que contribuirán a poner en circulación las nuevas referencias culturales en otros grupos de la sociedad. François-Xavier Guerra, Modernidad e independencias (Madrid: Mapfre, 1992), 99.

${ }^{8}$ Renán Silva, "Prácticas de lectura, ámbitos privados y formación de un espacio público moderno. Nueva Granada a finales del Antiguo Régimen", Los espacios públicos en Iberoamérica. Ambigüedades y problemas. Siglos XVIII-XIX, François-Xavier Guerra y Annick Lemperiere, eds. (México: Fondo de Cultura Económica, 1998), 80-81. Sobre las prácticas de lectura existentes en esta época en España, véase la versión sintética que propone Christian Peligry, "Le marché espagnol", en Histoire de l'édition française. Le livre triomphant (1660-1830), Roger Chartier y H. Martin, dir. (París: Fayard, 1990), 481492. Para una perspectiva orientada hacia la historia de la edición española, remítase a Víctor Infantes, François Lopez y Jean-François Botrel, Historia de la edición y de la lectura en España (1472-1914) (Madrid: Fundación Germán Sánchez Ruizpérez, 2003), en especial el capítulo: “Algunas formas editoriales", 368-390.

${ }^{9}$ Daniel Roche, La France des Lumières (París: Fayard, 1993), 399.
} 
residencias particulares o en la sede de la Real Biblioteca Pública de Santafé de Bogotá. Eran una forma de encuentro que se convirtió, poco a poco, en un vehículo para la circulación de nuevos libros y nuevos saberes. Allí se leía en forma colectiva, se discutía, se intercambiaban libremente opiniones, se confrontaban argumentos, utilizando recursos retóricos no muy usuales para la época, como el testimonio, la observación y la medición ${ }^{10}$.

A finales del siglo XVIII, estas nuevas prácticas de lectura empezaron a extenderse, lentamente, a los medios rurales. Testimonios de ello se encuentran en la correspondencia que sostuvieron entre sí distintos residentes de las ciudades pertenecientes al círculo ilustrado neogranadino con personas que habitaban el campo. Esta fuente epistolar, rica en información, como se ha señalado, pone en evidencia un elemento común: el deseo de relacionar lo que dice el libro con lo que el lector observa en su vida real, cotidiana, según se verá posteriormente ${ }^{11}$.

Hubo, asimismo, una más amplia circulación de gacetas, formas intermedias entre el libro y el periódico, que abordaban múltiples dimensiones del conocimiento. En Europa, a partir de 1730, se asiste a una progresión continua de estas publicaciones periódicas. Los Mercurios, cuyo título implica en sí mismo una función de intermediario diligente y oficioso, presentaban selecciones de libros, mezcladas con temas y crónicas de "actualidad", en las que el deseo de utilidad pública se expresaba con fuerza ${ }^{12}$. Entre fines del siglo XVIII y principios del XIX, se conocieron en la Nueva Granada, durante períodos no estrictamente contemporáneos, tres publicaciones semanales importantes, el Papel Periódico de Santafé (1791-1797), el Correo Curioso Erudito, Económico y Mercantil (1801) y el Semanario del Nuevo Reino de Granada (1808-1810).

Por otro lado, en el virreinato, el comercio del libro se encontraba también en transformación. Este proceso se evidencia, por ejemplo, en la pérdida del monopolio del comercio del libro por parte de la Iglesia; en la multiplicación de los pequeños comerciantes que se ocupaban del mercado del libro, y en la vinculación de comerciantes locales de cierto poder económico con la importación de libros, casi siempre a partir de la demanda de los lectores ${ }^{13}$.

\footnotetext{
${ }^{10}$ Silva, "Prácticas de lectura", 82.

${ }^{11}$ Ibídem.

${ }^{12}$ Jean Sgard, "La multiplication des périodiques", Histoire, ed. Chartier, 252-253. Gilles Feyel, "Periódicos", en Diccionario histórico de la Ilustración, Vincenzo Ferrone y Daniel Roche, eds. (Madrid: Alianza Editorial, 1988), 261-268.

${ }^{13}$ Se abandona así, poco a poco, el antiguo método de los procuradores de los conventos como distribuidores de libros y el de los comerciantes españoles residentes en la Metrópoli que mandaban libros a los puertos sin un conocimiento de la demanda. Véase en detalle este proceso en Renán Silva, Los ilustrados de Nueva Granada 1760-1808 (Medellín: Fondo Editorial Universidad EAFIT, 2002), 244.
} 
En este contexto, merece asimismo especial atención la fundación de la Real Biblioteca Pública de Santafé de Bogotá, la cual posibilitó una circulación más intensa de los textos y permitió el aumento de las corrientes de lectura, elementos claves dentro del proyecto de reforma universitaria que se había propuesto en el virreinato desde $1768^{14}$. La biblioteca generó un movimiento importante de usuarios y una utilización contínua de su espacio, ya que ahí funcionó durante muchos años una sociedad de lectura y de discusión, que a veces aparece llamada Tertulia Eutropélica y a veces, Asamblea del Buen Gusto.

Otra circunstancia que favoreció en forma importante los "viajes de los libros" de un lugar a otro del virreinato fue la instauración de una reforma del sistema de correos que quiso llevarse a cabo en este período ${ }^{15}$. Con la incorporación de los correos coloniales españoles a la Corona, en 1768, tuvo lugar su reorganización total en América española ${ }^{16}$. En la Nueva Granada, ella estuvo a cargo de Joseph Antonio de Pando, quien residió en Cartagena entre 1769 y 1771 y ratificó la Oficina de Correos de Santafé como sede postal, con sucursales en Popayán, Cartagena, Cartago y Honda ${ }^{17}$. La organización establecida por Pando se completó años después con una Real Cédula (Aranjuez, 8 de junio de 1794) y constituye la primera base del sistema postal colombiano, que perdurará, con algunas reformas, apenas sutiles, hasta $1859^{18}$.

Es característica fundamental de estas nuevas prácticas de lectura en la Nueva Granada la más intensa presencia de ciertas publicaciones en las bibliotecas, en los pedidos o en las compras: los libros de ciencias (matemáticas, botánica, física) y de historia natural, categoría que en aquella época comprendía tanto los libros de

\footnotetext{
${ }^{14}$ Sobre este tema, véase Renán Silva, Universidad y sociedad en el Nuevo Reino de Granada. Contribución a un análisis histórico de la formación intelectual de la sociedad colombiana (Bogotá: Banco de la República, 1993).

${ }^{15}$ Para resolver la situación crítica que enfrentaba la Nueva Granada a causa de la ausencia de un correo institucional, el Virrey José Alfonso de Pizarro, por decreto del 10 de junio de 1750, había establecido, por iniciativa propia, los primeros servicios postales organizados, con itinerarios fijos, tarifas y regulaciones detalladas. Creó las siguientes líneas de correo: Santafé-Popayán-Quito (1750); Santafé-Cartagena (1750); Santafé-Maracaibo (1751); Santafé-Opón (1757) y Popayán-Cartago (1762). Mario Arango Jaramillo, Augusto Peinado y Juan Santa María, Comunicaciones y correos en la historia de Colombia y Antioquia (Bogotá: Editorial Gente Nueva, 1996), 31-33.

${ }^{16}$ En la península, los ingresos de los correos se incorporaron a la Corona en 1706, y en las colonias americanas solo a partir de 1768, cuando se consideró como definitivamente terminado el privilegio del "correo mayor" mediante un acuerdo suscrito el 13 de octubre del mismo año (1768). Ibídem, 33.

${ }^{17}$ Ibídem, 33-34.

${ }^{18}$ Ibídem, 33.
} 
medicina, fisiología y cirugía como los manuales de higiene y salud, que se estudiarán a continuación.

\section{Los manuales de salud}

Los manuales de salud pertenecen a una tradición que proviene de la llamada "medicina para pobres", cuyo inicio data del siglo XVI y que tiene un origen común: los antiguos preceptos de la Escuela de Salerno, aparecidos en forma masiva durante el siglo XVII. El libro más famoso de esta célebre escuela de medicina, fundamentalmente práctica, fue el Regimen Sanitatis Salernitanus, también conocido como Flos Medicinae Salerni ${ }^{19}$. Los manuales de salud publicados a partir de la segunda mitad del siglo XVIII se sitúan en la misma perspectiva que los tratados de medicina para pobres, bien sea para prolongarlos, comentarlos, criticarlos o bien para inspirarse en ellos.

En general, estos dos tipos de libros revelan la preocupación por acceder a un saber, por informar e instruir, y persiguen dos objetivos esenciales: llegar a los intermediarios culturales para alcanzar mejor al pueblo y reaccionar contra la charlatanería y los daños que esta producía. Para cumplir con sus objetivos, cada uno de estos géneros se sirve de medios diferentes: el de la medicina para pobres privilegia la medicina curativa, para lo cual aporta recetas, listas de remedios y fórmulas diversas utilizadas contra las enfermedades. El otro, específico del siglo XVIII, pone más énfasis en la higiene y en la prevención; por ende, allí se nota un deseo más pedagógico. Otro elemento importante que marca la diferencia es que en el siglo XVII buena parte de esta literatura fue escrita en latín, mientras que los manuales del XVIII fueron escritos en lenguas vernáculas ${ }^{20}$.

En el siglo XVII y hasta mediados del siglo XVIII, este tipo de libros eran escritos generalmente por sacerdotes o por damas de caridad y revelaban el espíritu de esta virtud teologal: la obligación de socorrer a los pobres en nombre de la ley divina. Los autores se sentían investidos de una misión caritativa, ellos eran los apóstoles, indispensables para auxiliar a los pobres, en un deber de asistencia que participaba de la manutención de un orden social incontestable e inmutable.

\footnotetext{
${ }^{19}$ Esta obra se tradujo a por lo menos ocho idiomas y en 1846 ya se habían realizado 240 ediciones. El Régimen consta de 10 secciones: higiene, drogas, anatomía, fisiología, etiología, semiología, patología, terapéutica, clasificación de las enfermedades y práctica de la medicina. Se trata de una serie de observaciones, escritas en latín versificado, sencillo y claro, de simples consejos racionales, en los que no se hace apelación alguna a las autoridades, a la magia o los astros. Sobre la escuela de Salerno, véase: Charles Victor Daremberg, La médecine, histoire et doctrines, 2 ed. (París: Didier, 1855), 123-144.

${ }^{20}$ Mireille Langet y Claudine Luu, Médecine et chirurgie des pauvres (París: Privat, 1984), 24. Daniel Teysseire y Corine Verry-Jouvet, "Présentation", en Avis au peuple sur sa santé Samuel Tissot (París: Chez P. Fr. Didot, 1782; París: Quai Voltaire Histoire, 1993).
} 
En los manuales de mediados del siglo XVIII, el médico tiene un papel esencial, y las preocupaciones por el estado de salud de la población facilitan la expresión de la profilaxia y de la higiene que se proclama en la tradición hipocrática. En aquella época, el problema demográfico será central en este tipo de preocupaciones, pero si bien los autores buscaban disminuir la mortalidad en el pueblo, no pensaban ya en ella como en una fatalidad contra la cual el hombre no podía obrar y, por lo contrario, consideraban imprescindible instruir al pueblo en los peligros que corría si no cuidaba su salud. Lo que subyace en estos nuevos textos es la convicción de que el hombre puede luchar contra la enfermedad y contra la muerte. Es tal la certeza que los anima, que se rehúsan a considerarlas como ineluctables y preconizan medidas para limitarlas. Desde sus títulos es posible entrever dos ideas: un reto a la enfermedad y a la muerte y el deseo de hacer durar la vida el mayor tiempo posible ${ }^{21}$.

Desde otro punto de vista, la estructura de los tratados del siglo XVII obedece a un modelo distinto de los del siglo XVIII. En los primeros, se encuentra una enumeración anárquica de preparaciones y/o de medicamentos, a veces clasificados por categorías según fueran jarabes, píldoras, aceites, etc., y según las enfermedades fueran de la cabeza, del estómago, fiebres, etc.; los segundos se estructuran en un régimen de vida, generalmente seguido de una lista de remedios y de máximas para conservar la buena salud. En estas últimas obras, la explicación de las causas de las enfermedades es de una gran simplicidad y el tratamiento que se aconseja tiene que ver más con una higiene de vida que con una medicina muy compleja. Entre las causas que explican las dolencias, ocupan un lugar especial la fatiga, las variaciones climáticas o la calidad del aire y de la alimentación ${ }^{22}$.

A partir de la segunda mitad del XVIII, la importancia que cobran estas obras es el signo de un proceso que favorecerá la aparición de la conciencia de que la salud

${ }^{21}$ François Lebrun, Se soigner autrefois. Médecins, saints et sorciers aux XVII et XVIII siècles (París: Points-Seuil, 1995), 20; véase, asimismo, Arlette Farge, "Se conserver en santé au XVIII siècle. D'après les guides, dictionnaires ou arts de se conserver en santé", en Le corps, la santé, la maladie. Travaux et Recherches du Groupe d'Histoire Moderne et Contemporaine du CNRS (París: CNRS, 1979), 18-26.

${ }^{22}$ El deseo de perfeccionar la aproximación práctica es evidente en las obras escritas a partir de la segunda mitad del siglo XVIII. El Avis au peuple de Tissot, por ejemplo, insiste en la descripción de las enfermedades y trae al final una tabla de remedios con diversas notas. Cada remedio tiene un número que reenvía a los capítulos donde ha sido citado. Este sistema permite cruzar dos tipos de investigación o de búsqueda: un remedio para cada enfermedad y cada enfermedad con su remedio. Este funcionamiento marca también una evolución en relación con las obras anteriores de medicina para pobres, donde a menudo el índice no distinguía los males de los remedios. Teysseire, "Présentation". 
debe contemplarse desde una perspectiva colectiva y no solo como un problema individual $^{23}$.

\section{Los usos locales}

Es significativo el número de manuales de salud nombrados en las correspondencias, ya se trate de los existentes en las bibliotecas de los ilustrados neogranadinos o de los citados en sus escritos y en sus artículos ${ }^{24}$. Después de esta constatación, es necesario considerar que la posesión de un libro no es sinónimo de su lectura efectiva. Tal presencia puede poner en evidencia más los intereses, los anhelos, los ideales o, si se quiere, los temores que forman parte del universo cultural de un grupo determinado en un momento específico (valoración de la salud personal y colectiva, preocupación por el futuro y deseo de felicidad, cierto afán de prevención, etc.), pero muestra menos su vinculación con la lectura y con las prácticas mismas.

Del mismo modo, cabe recordar que un libro leído no es necesariamente un libro que se posee. El libro puede venir de circuitos diferentes, puede ser prestado o puede ser consultado en una biblioteca; debe recordarse, en este sentido, que existieron "librerías" en los colegios capitalinos (El Rosario y San Bartolomé) y algunas otras de carácter privado (como las de José Celestino Mutis y Antonio Nariño) que tuvieron un uso colectivo. Igualmente, por esta época iniciaba sus labores la Real Biblioteca Pública de Santafé de Bogotá, como se ha señalado; sin embargo, ninguno de los libros aquí estudiados formaba parte de esta última en su fundación, quizá ellos solo empiezan a entrar tiempo después. En el momento de su apertura, esta biblioteca era un depósito ${ }^{25}$, abastecido con los libros pertenecientes a la biblioteca de los jesuitas hasta el momento de su expulsión (1767), en la cual eran escasas las obras médicas ${ }^{26}$.

${ }^{23}$ Enrique Perdiguero Gil, "Los tratados de medicina doméstica en la España de la Ilustración" (Tesis doctoral, Universidad Alicante, 1990), 8.

${ }^{24} \mathrm{~A}$ título de ejemplo, y sin pretensiones de exhaustividad, fuera de las personas que son citadas en este trabajo, se tiene noticia de que poseían los libros de Tissot y Buchan: el abogado Emigdio Troyano, quien realizó estudios en el Colegio San Bartolomé y frecuentaba los círculos de naturalistas; el clérigo Rueda, cura de la ciudad de Neiva; el pbro. de Bosa, Francisco de Valenzuela; el médico Miguel de Isla; Don Juan José D'Elhuyar; Antonio Nariño (en el inventario de su biblioteca aparece W. Buchan). Entre los poseedores de la obra de Mme. de Fouquet estaba Jorge Tadeo Lozano. Bernardo Caycedo, D'Elhuyar y el siglo XVIII (Bogotá: Kelly, 1971); Renán Silva, Los ilustrados.

${ }^{25}$ José Antonio Amaya, "Una flora para el Nueva Reino. Mutis, sus colaboradores y la botánica madrileña (1791-1808), en Diana Obregón, ed., Culturas científicas y saberes locales (Bogotá: Universidad Nacional de Colombia, CES, 2000), 106-107.

${ }^{26}$ La mayor parte de esta biblioteca estaba constituída por obras teológicas; en el inventario se recogen las siguientes áreas temáticas: Santos Padres, Expositores, Theologi, 
Sin embargo, es posible encontrar en diversas fuentes, como se ha dicho, algunos indicios que sirven para rastrear la lectura de este tipo de textos entre diversos personajes neogranadinos. La élite cultural neogranadina leyó durante esta época algunos manuales publicados durante el siglo XVII; entre ellos, ocupa el primer lugar el célebre tratado de Madame Fouquet Recueil des remèdes faciles et domestiques (1675), que contaba ya en 1740 con 16 reediciones $^{27}$; también se conoció el Méthode naturelle de guérir les maladies du corps et les déréglements de l'esprit qui en dépendent (1742), del médico inglés George Cheyne (16711743).

Pero las obras de esta naturaleza que aparecen con mayor frecuencia en las bibliotecas de la Nueva Granada durante este período -vale decir, las que eran citadas, mencionadas o solicitadas más a menudo- fueron las publicadas a partir de mediados del siglo XVIII, especialmente: Avis au peuple sur sa santé (1761) de S. A. Tissot; Domestic Medicine (1769), de William Buchan; Tratado da conservaçao da saúde dos povos (1756), de Antonio Nunes Ribeiro Sanches ${ }^{28}$; Le conservateur de la santé (1763), de Achille Guillaume Le Begue de Presle ${ }^{29}$; Art de prolonger la

Conciolatores, Canonistas; Mathematici; Grammatici; Históricos; Vidas de Padres de la Compañía de Jesús; Vidas de Santos y Santas; Espirituales, Medici, Moralistae. El porcentaje de libros relacionados con la medicina era bastante bajo; de las 2.353 obras que tenía la biblioteca, solo $21(0,9 \%)$ trabatan de esta materia. Entre esos libros, sobresalen la Materia Médica de Dioscórides, la Opera Médica de Galeno y una edición de 1588 de las Obras de Hipócrates en latín. José del Rey Fajardo, La biblioteca colonial de la Universidad Javeriana de Bogotá (Caracas: Pontificia Universidad Javeriana, Universidad Católica del Táchira, s. f. ), 577-582.

${ }^{27}$ Madame-Marie Fouquet (1590-1681) fue también autora del Recueil de receptes, où est expliquée la manière de guérir à peu de frais toutes sortes de maux. Le tout a été expérimenté par les charitables soins de Mme. Fouquet (Lyon: Certe, 1676).

${ }^{28}$ Sobre la circulación de Tissot y Buchan en España y, en general, sobre los manuales de medicina doméstica en la España del siglo XVIII, véanse los estudios de Enrique Perdiguero Gil, "The popularization of medicine during the Spanish Enlightenment", en The Popularization of Medecine 1650-1850, Roy Porter (Londres-Nueva York: Routledge, 1992), 160-193; del mismo autor, su tesis: "Los tratados de medicina"; además, de Ángel González de Pablo, "Sobre la configuración del modelo de pensamiento de la higiene actual: el caso español", Dynamis. Acta Hisp. Med. Sci. Hist. Illus. (Málaga), 15 (1995): 267-299; Rafael Alcaide González, "Las publicaciones sobre higienismo en España durante el período 1736-1939. Un estudio bibliométrico", Scripta Nova (Barcelona), 37 (abril, 1999); Juan Riera, Capitulos de la medicina española ilustrada. Libros, cirujanos, epidemias y comercio de quina (Valladolid: Universidad de Valladolid, 1992).

${ }^{29}$ Achille Guillaume Le Bègue de Presle (1735-1807). Médico francés, autor de diversas obras y artículos sobre medicina e higiene. Encargado de la edición científica del Avis au peuple sur sa santé, realizada en París (chez Didot le Jeune) en 1762; fue médico de J. J. Rousseau. En el Fondo Antiguo de la BNC se encuentra la siguiente traducción española: El conservador de la salud, ó aviso a todas las gentes acerca de los peligros que les 
vie et de conserver la santé (1786), de Jean B. Pressavin ${ }^{30}$, y los Avisos médicos populares y domésticos (1776), de Antonio Pérez de Escobar ${ }^{31}$.

\section{EI argumento de autoridad}

Entre los libros que a menudo eran citados como argumento de autoridad para justificar el establecimiento de medidas de salud pública en la Nueva Granada se encuentra, en primer lugar, el Avis au peuple sur sa santé (1761), de Samuel André Tissot $^{32}$. El Avis fue uno de los más importantes tratados de medicina popular del siglo XVIII y además es considerado el texto fundador de la medicina social. Ocupó un lugar central en las lecturas de los ilustrados europeos, españoles y neogranadinos. Esta obra fue una referencia clave en el proceso de apropiación de

importa evitar para mantenerse con buena salud, y prolongar la vida; traducido al español por Don Félix Galisteo y Xiorro.

${ }^{30}$ Jean Baptiste Pressavin (n. 1734), médico francés, ejerció en Lyon y fue además autor de Traité des maladies des nerfs (París: J.P. Costard, 1769), Traité des maladies venériennes (Geneve: Didot, 1773).

${ }^{31}$ También pueden citarse en esta lista: Traité de Médecine Legale et d'Hygiène Publique ou de Police de Santé (París: Croullebois, 1799), de F. E. Fodéré (1764-1835), quien fue, asimismo, autor del Essai sur le goître et le crétinisme précédé d'un discours sur l'influence de l'air humide (París: Chez Bernard, Libraire pour les Mathématiques, Sciences et Arts, Quai des Augustins, 1800), y era conocido y citado por Caldas, cuando trata sobre el coto en la Nueva Granada. Francisco José Caldas, "Sobre el influjo del clima en los seres organizados", en Semanario del Nuevo Reino de Granada, t. 1 (Bogotá: Biblioteca Popular de Cultura Colombiana, 1942), 190; Jean Joseph Sue, Dictionnaire portatif de santé : dans lequel tout le monde peut prendre une connaissance suffisante de toutes les maladies, des différents signes qui les caractérisent chacune en particulier, des moyens les plus surs pour s'en préserver, ou des remèdes les plus efficaces pour se guérir, 6 ed. revue et corr (París: Chez Josep Barbou, 1777). Este diccionario se encuentra en el Fondo Antiguo de la BNC, con el sello de la Real Biblioteca Pública de Santafé.

${ }^{32}$ Samuel André Tissot (1728-1797), nació en Lausana y realizó estudios de medicina en Montpellier; de regreso a su ciudad natal, el Consejo de la ciudad lo nombra médico de pobres en 1751. Fue profesor de medicina en Pavia (1781) y vicepresidente del Colegio de Medicina de Lausana (1787). Otras de sus obras son: L'inoculation justifiée (1754), Dissertatio de febribus biliosis (1758), L'onanisme (1760); De la santé des gens de lettres (1768), Traité des nerfs (1780). Mantuvo, además, una importante correspondencia con Rousseau y con Voltaire. Antoinette Emch-Deriaz, Tissot, Physician of the Enlightenment, (Nueva York: Lang, 1992). Su obra Avis au peuple aborda, entre otros, los siguientes temas: algunas causas de las enfermedades del pueblo; lo que debe hacerse al comienzo de las enfermedades; la dieta que debe observarse durante las enfermedades agudas; la inflamación del pecho; el dolor de garganta; los resfriados; el dolor de muelas, la apoplejía, las insolaciones, el reumatismo; la viruela, la rubéola; los diferentes tipos de fiebre; las pleuresías; los cólicos, el cólera morbus; la diarrea, la disentería; la sífilis. El texto trae también un Aviso a las mujeres y un Aviso a los niños, y un aparte consagrado a las enfermedades quirúrgicas y externas. 
las nuevas nociones de saber referidas a la medicina, al problema del contagio y a otros aspectos relativos a la salud pública en la Nueva Granada durante tal período. En los círculos ilustrados neogranadinos este libro era llamado El Tissot ${ }^{33}$. Fue asimismo uno de los libros más leídos en su momento, tanto en Europa (constituyó un verdadero best-seller en la época, éxito del que dan cuenta las 18 ediciones publicadas durante la vida del autor (1761-1792), en solo tres ciudades: Lyon, Lausana y París -salía, en promedio, una edición cada 20 meses- $)^{34}$, como en América. En Ecuador, por ejemplo, Eugenio Espejo (1747-1795) lo cita en repetidas oportunidades en sus escritos, y fue también orientador del pensamiento médico en el Perú ${ }^{35}$.

El Avis resultó primordial a las autoridades virreinales para enfrentar las epidemias de viruela que azotaron la Nueva Granada en 1782 y 1802, pues fue una guía esencial en cuanto a la exposición de las virtudes de la inoculación, al método para realizarla y al tratamiento que debía darse a los enfermos. Los principales escritos de José Celestino Mutis sobre la viruela -el "Método general para curar las viruelas" y "Sobre las precauciones que deben observarse en la práctica de la inoculación de las viruelas" (1783) - buscaban prevenir los nefastos resultados de la inoculación mal dirigida y ofrecer recetas y observaciones para su tratamiento; según el autor: "[estaban] arregladas al método del mencionado Tissot, a cuya lección se persuade al público citándolo con todo el honor que se merece. Y siendo tal el concepto que he formado del sabio médico Tissot, desde que conocí sus obras en Europa" ${ }^{36}$. Estos escritos, redactados a petición del Virrey Caballero y Góngora,

\footnotetext{
${ }^{33}$ La primera traducción castellana del Avis fue realizada por el religioso José Fernández Rubio en 1773, a partir de la edición hecha en París por Didot le Jeune en 1767. La segunda edición española se llevó a cabo en 1774 por Juan Galisteo y Xiorro (esta fue reeditada en 1776, 1778, 1781, 1790 y 1795). Enrique Perdiguero Gil, "Popularizando la ciencia: el caso de la medicina doméstica en la España de la Ilustración", en La Ilustración y las ciencias. Para una historia de la objetividad (Valencia: Universitat de Valencia, 2003), 162.

${ }^{34}$ Daniel Teysseire, "Aux origines de la médecine sociale et de la politique de la santé publique: 1'Avis au peuple sur sa santé de Tissot", Mots. Les langages du politique (París), 26 (1991): 47.

${ }^{35}$ Véase Juan B. Lastres, Historia de la medicina peruana, vol. 2, La medicina en el virreinato (Lima: Imprenta Santa María, 1951), 267. También, J. H. Unanue, "Decadencia y restauración del Perú. Oración inaugural que, para la estrena y abertura [sic] del Anfiteatro anatómico, dijo en la Real Universidad de San Marcos el día 21 de noviembre de 1792”, El Mercurio Peruano, (Peru), núm. 218-222 (3, 7, 10, 14 y 17 de febrero de 1793), en Jean-Pierre Climent, El Mercurio Peruano, 1790-1795, vol. 2, Antología (Madrid: Vervuert-Frankfurt, Iberoamericana, 1998), 225-228.

${ }^{36}$ En el Avis au peuple, los capítulos 13 y 23 están consagrados a la viruela y la inoculación, respectivamente.
} 
orientaron en gran parte la política sanitaria que las autoridades locales instauraron para controlar estos fenómenos epidémicos ${ }^{37}$.

En relación con la lectura de Tissot y las epidemias de viruela, también puede verse la carta que Mutis dirige al Virrey Mendinueta (1802), donde le comunica su aprobación de los documentos que había remitido al mismo virrey el gobernador de Santa Marta, Antonio de Narváez, en los cuales anunciaba la elección del Avis como libro básico para realizar la inoculación en su región:

En confirmación de tan acertada elección podrá servir el alto concepto que logra este autor en casi todas las Provincias de este reino, cuya obra se ha esparcido entre los curas, debiendo la Humanidad este señaladísimo beneficio al celo de vuestra excelencia desde su llegada a esta capital, quien reconociendo la falta de profesores se dignó suplir de algún modo la necesidad, repartiendo, a sus expensas, la obra de Aviso al pueblo traducida al castellano (...) Pudiendo vuestra excelencia tener la cumplida satisfacción de haber sido el primero que dio a conocer en este Reino una obra tan recomendable y utilísima, en lugar de otras mucho menos ventajosas que andaban en las manos del pueblo ${ }^{38}$.

Meses después, el mismo gobernador comunica al virrey que la epidemia de viruela que había asolado a Santa Marta y su provincia no se estaba extendido a la zona del Valledupar gracias a las medidas tomadas, procedentes de un libro del "médico Simon André Tis[s]ot", del cual le enviaba dos capítulos copiados ${ }^{39}$.

El papel de los curas como intermediarios o passeurs culturels aparece aquí enunciado de manera clara. Obras como las de Tissot $u$ otras de su género fueron escritas generalmente por médicos para sanar o prevenir las enfermedades del pueblo, pero estaban destinadas a ciertos grupos sociales que servían de enlace entre este y aquellos. El verdadero usuario en la Nueva Granada fue una minoría ilustrada, que actuaba como mediadora en un proceso que pretendía transmitir al

37 Guillermo Hernández de Alba, comp., Archivo epistolar del sabio naturalista José Celestino Mutis, t. 2 (Bogotá: Kelly, Instituto Colombiano de Cultura Hispánica, 1975), 166; véase Silva, Las epidemias, 31-60 y Adriana María Alzate, Los oficios médicos del sabio. Contribución al estudio del pensamiento higienista de José Celestino Mutis, (Medellín: Universidad de Antioquia, 1999), 35-56.

${ }^{38}$ Hernández de Alba, Archivo epistolar, 166. Resaltados de la autora.

39 Archivo del Real Jardín Botánico de Madrid (ARJBM) (Madrid). Expediciones Científicas, Expedición de José Celestino Mutis, sig. III, 2,3, 78. Sobre el uso que en ocasiones hicieron los gobiernos de este tipo de obras, puede también verse el caso de Francia, donde las autoridades publicaban $-\mathrm{o}$ adquirían para distribuirlos- libros para educar al público en cuestiones relacionadas con la salud, entre los cuales el más popular fue el de Tissot. George Rosen, "El mercantilismo y la política para la salud en Francia", en De la policía médica a la medicina social (México: Siglo XXI, 1985), 243. 
resto de la población un saber sobre diferentes aspectos de la salud. En este proceso, los curas cumplieron una función de mediadores en el virreinato ${ }^{40}$.

En el mismo contexto de la epidemia de viruela, pero ya en un medio rural, puede verse el proceso judicial (1802) que se le sigue al hacendado Ignacio Cortés, acusado de haber ocultado y protegido en su casa de campo, situada en el pueblo de Hobo (provincia de Neiva), a un enfermo de viruela, violando así las disposiciones que lo prohibían, las cuales mandaban denunciarla ante las autoridades competentes. En una de las etapas del proceso, el hacendado critica el proceder del "práctico de medicina" del pueblo, por no haber hecho un diagnóstico acertado de la enfermedad del paciente en cuestión, "ya que confirmó que eran viruelas sin registrar al enfermo, [y] sin verle la cara más que confusamente". Agregaba luego: "Estos médicos o curanderos tan perjudiciales son los que llama el célebre Tis[s]ot, autor médico, que sin averiguar los síntomas de la enfermedad y sin ver más que de lejos al paciente, declaran con egoísmo, este tiene tal enfermedad; y como homicidas y polillas de la república, deben desterrarse" ${ }^{\text {" }}$.

La obra del médico suizo se encuentra también presente cuando se trata de explorar en la Nueva Granada las dos principales polémicas que ocuparon la reflexión médica sobre la muerte a finales del siglo XVIII: la preocupación por el espacio, el sitio del enterramiento, y la relativa al tiempo de espera entre la muerte y la inhumación del cadáver.

En cuanto a la primera inquietud, en los informes que algunos de los médicos neogranadinos redactaron para explicar a las autoridades virreinales los beneficios de desplazar los cementerios fuera de las poblaciones, se apela frecuentemente a Tissot. Es claro que el médico suizo inspiró varios de estos escritos, pero sólo Antonio Froes lo cita explícitamente en su texto sobre esta temática ${ }^{42}$. A su juicio,

\footnotetext{
${ }^{40}$ Este papel de mediadores se puede apreciar también, por ejemplo, en el Papel Periódico de Santafé de Bogotá (1795), el cual publica una real orden sobre unos remedios que se habían descubierto en Cuba para tratar el "mal de siete días" (el aceite canimar y el bálsamo de copayba). Esta enfermedad era padecida especialmente por los recién nacidos en algunas regiones del virreinato. El editor del periódico hace notar que ese impreso se distribuía también de manera gratuita en la imprenta del periódico, pero solo a los curas, corregidores y padres de familia que quisieren llevarlo a sus pueblos. Papel Periódico de Santafé de Bogotá (Bogotá), 224 (diciembre 25 de 1795), 1-2.

${ }^{41}$ Citado por Silva, Las epidemias, 124. El capítulo XXXV del libro de Tissot trata sobre los charlatanes y los magos (des charlatans et des maîges).

${ }^{42}$ Froes había llegado a Santafé en 1778; entonces le fue concedida licencia para ejercer como médico y se lo nombró asimismo visitador de boticas. Se tiene noticia de que en 1792 inspeccionó las boticas de la ciudad y dio orden de cerrar algunas por carecer de personas competentes en su gestión. Su hijo Manuel Froes se dedicó también a la medicina e hizo parte de las personas que fueron tomadas presas junto con Antonio Nariño en 1794. Algunos autores, como Martínez Zulaica, hacen notar la confusión sobre la persona y la
} 
era superfluo continuar justificando los beneficios de construir cementerios fuera de los poblados, como lo habían hecho ya la mayor parte de los "sabios físicos y médicos" de entonces en Europa y aun algunos otros en América y en la Nueva Granada. Para explicar las nefastas consecuencias de dicha práctica, Froes trata acerca de los efectos de la humedad de las iglesias (que estaban cerradas "las dos partes del día natural"); de la poca ventilación, además de las constantes exhalaciones de los cuerpos enterrados que podrían la atmósfera del templo; así, el aire cargado con todos estos vapores penetraba en los cuerpos de los feligreses cuando asistían a los oficios divinos, causándoles enfermedades y en ocasiones hasta la muerte. Para estudiar las causas de la corrupción general de la atmósfera producida por el entierro -dice- se había servido "de textos y tratados que circulaban en la época". Entre ellos, menciona expresamente que Tissot consideraba las sepulturas abiertas como manantiales de vapores pestíferos, porque, aunque contínuamente se estaban evaporando, "siempre quedan en ellas las partículas térreas corrosivas y pudridas de los huesos" $"$.

La segunda preocupación, relativa al tiempo de espera entre la muerte y la inhumación del cadáver (vinculada con el terror de ser enterrado vivo) ${ }^{44}$, también estuvo presente en este círculo cultural de la Nueva Granada con varios artículos de prensa sobre el tema, como lo atestiguan algunos libros encontrados en los inventarios de las bibliotecas y otros documentos ${ }^{45}$. En el artículo sobre las asfixias

nacionalidad de este médico, pues en ocasiones algunos indican que era portugués y otros que era un francés proveniente de la isla de Santo Domingo, que había estudiado en Montpellier; en Antonio Martínez Zulaica, La medicina en el siglo XVIII en el Nuevo Reino de Granada (Tunja: Universidad Pedagógica y Tecnológica de Colombia, 1972), 291-292. Según Ibáñez, era un médico portugués llegado a Santafé en 1780, en Pedro María Ibáñez, Crónicas de Bogotá, t. 1 (Bogotá: Biblioteca Cultural de Cultura Colombiana, 1951), 175). Gredilla anota que en 1782 era el médico del Arzobispo Virrey Caballero y que en una ocasión había sido calificado por Mutis como un "médico (...) y profesor de toda mi estimacion”, en Federico Gredilla, José Celestino Mutis (Bogotá: Plaza y Janés, 1982), 67.

${ }^{43}$ Archivo General de la Nación (AGN) (Bogotá), Archivo Anexo, Historia, t. 3, fols. 450$457 \mathrm{v}$.

${ }^{44}$ Sobre este tema, remítase, entre otros, a Claudio Milanesi, Mort apparente, mort imparfaite. Médecine et mentalités au XVIII siècle (París: Payot, 1991). Paula de Demerson, "Muertes aparentes y socorros administrados a los ahogados y asfixiados en las postrimerías del siglo XVIII", Asclepio (Madrid, CSIC)), 53, núm. 2 (2001): 45-68.

${ }^{45}$ Véase, por ejemplo, Papel Periódico de Santafé de Bogotá (Santafe de Bogotá), núm. 134, 135 y 175, años 1793-1795; Correo curioso, erudito económico y mercantil de Santafé de Bogotá (Santafé de Bogotá), 4 de agosto de 1801, 121. Se encontraron algunos libros relativos a esta temática en los inventarios de varias de las bibliotecas de los ilustrados. En la de Antonio Nariño, por ejemplo, se hallaba: Jean-Jacques Bruhier, Dissertation sur l'incertitude des signes de la mort et abus des enterrements et embauments précipités (París: Bure, 1749); véase Eduardo Ruiz Martínez, La librería de Nariño y los Derechos del Hombre (Bogotá: Planeta, 1990), 132. En la Biblioteca Real de Santafé se encontraban: 
o muertes aparentes, publicado en el Papel Periódico de Santafé de Bogotá (1795) y escrito por el sacerdote santafereño Don Nicolás Moya de Valenzuela, este hace alusión a la última parte de una de las traducciones españolas del Avis au peuple sur sa santé (1790), que anexaba el "catecismo de Gardane [Joseph-Jacques] sobre las asfixias" ${ }^{\prime 6}$. El sacerdote aconseja que aquellos que podía suponerse ya muertos de asfixia o de manera repentina debían ser enterrados cuatro o cinco días después de la presunta muerte, con el fin de evitar que se enterrasen estando aún vivos ${ }^{47}$.

Otra de las dimensiones en las que este tipo de libros pudo haber sido útil es la relacionada con la institución hospitalaria. A finales del siglo XVIII, se conocieron en la Nueva Granada varios proyectos de creación o de reforma hospitalaria en los cuales se nota la influencia de algunas disposiciones metropolitanas y de los manuales de salud. El Avis au peuple, por ejemplo, destina gran parte de sus capítulos a sugerir dietas y a explicar su necesidad para las distintas etapas de las enfermedades; igualmente, Buchan, en la segunda parte de Domestic Medicine, se ocupa, entre otros, de este tema.

El Tratado da conservaçao da saúde dos povos también formó parte importante de las lecturas ilustradas en materia de salud. Esta obra del médico portugués Antonio Nunes Ribeiro Sanches (Penamacor 1699-París 1783) fue traducida al español por el arquitecto y matemático Benito Bails y publicada en Madrid por Joachim de Ibarra, en $1781^{48}$. El autor realizó estudios de medicina y filosofía en Coimbra, se

Jacques-Joseph Gardane, Catéchisme sur les morts apparentes dites asphyxies ou instruction sur les manières de combattre les différentes espèces de morts apparentes (Paris: Valade, 1771) y Antoine Louis, Lettres sur la certitude des signes de la mort, ou l'on rassure les citoyens de la crainte d'être enterrés vivants (París: Chez Michel Vambert, 1752).

46 Joseph-Jacques Gardanne, médico francés, realizó sus estudios en la Facultad de Medicina de Montpellier y ocupó la regencia de la Facultad de Medicina de París. En sus investigaciones se interesó por la higiene pública, por las enfermedades de los artesanos y por las "clases pobres", así como por la búsqueda de los medios para disminuir la propagación de las enfermedades venéreas. Fue también autor de Manière sûre et facile de traiter les maladies vénériennes (1773), entre otras. Guyot de Fere, "Gardane, JosephJacques”, en Nouvelle biographie générale, t.19 (París: MM. Firmin Didot Frères, 1858), 472.

${ }^{47}$ Don Nicolás Moya de Valenzuela, Papel Periódico de Santafé de Bogotá (Bogotá), núm. 175, 16 enero de 1795, pp. 974-979.

${ }^{48}$ Benito Bails (Barcelona 1730-Madrid 1797). Matemático y preceptista español. Hizo sus primeros estudios en la Universidad de Toulouse y luego en París, donde se dio a conocer por trabajos de diversa índole. De regreso a Madrid, fue nombrado académico de número de las academias de la Lengua y de la Historia y director de la Sección de Matemáticas de la de San Fernando. Entre sus otras obras, se encuentran: Diccionario de arquitectura civil, Lecciones de clave y principios de armonía (Madrid: Imp. Viuda de Ibarra, 1775), Instituciones de geometría práctica (Madrid: Imp. Viuda de Ibarra, 1795). El trabajo del 
doctoró en Salamanca (1724) y continuó su formación en Londres, París, Montpellier y Leiden, donde fue alumno de Boerhaave. Se trasladó posteriormente a Rusia por indicación de este último y allí fue nombrado protomédico de Moscú (1731), ocupó luego el puesto de médico de Petersburgo (1733), de médico de la Armada Imperial (1733) y, más tarde, médico de Catalina II (1740). Hizo una importante contribución a la organización de los estudios médicos en Rusia (Moscú y San Petersburgo) y en Portugal. Escribió el artículo sobre venerología de L'Encyclopédie y pasó sus últimos días en Francia, ejerciendo la medicina en beneficio de los pobres. Fue también autor de obras pedagógicas: Método para aprender e estudar a Medicina (1763), Cartas sobre a educação da mocidade $(1760)^{49}$.

En su Tratado, Sanches aborda en profundidad varios de los temas relacionados con la sanidad de las ciudades y poblaciones: reflexiones sobre los sitios más sanos para fundar las ciudades, las repercusiones higiénicas de la morfología urbana; la construcción de edificios, hospitales, cárceles y cuarteles; la localización de los "focos de contagio", etc. La tarea de acompañamiento médico a los ejércitos rusos en su campaña contra los turcos le aportó a Sanches una vasta experiencia clínica e higiénica que plasmó luego en su obra ${ }^{50}$.

Por su parte, aunque Benito Bails no fue médico ni escribió ningún tratado o manual de salud, es importante destacar su interés por la salud de las poblaciones. Es un aspecto de su obra que ha sido poco estudiado, en privilegio de su labor como matemático. Una gran parte de una de sus obras: Elementos de matemática, trata sobre temas relativos a la arquitectura y la salud pública. Esta obra de Bails, de amplia circulación en la Nueva Granada durante la época, era muy común en los inventarios de las bibliotecas y fue fundamental para el estudio de las matemáticas entre la élite local; pudo haber tenido un uso similar a los libros sobre salud que se comentan aquí para justificar el establecimiento de medidas de salud pública.

arquitecto y matemático español fue publicado entre 1779 y 1790 en nueve volúmenes. Su redacción le había sido encargada por la Real Academia de San Fernando.

${ }^{49}$ Respecto a la vida y obra de este médico portugués, véase José Luis Doria, "Antonio Ribeiro Sanches: a portuguese doctor in $18^{\text {th }}$ century Europe", Vesalius, Acta Internationalis Historiae Medicinae (Bruselas), 7, núm. 1 (junio 2001): 27-35. Sobre Sanches existe, asimismo, un interesante elogio que le hace el médico francés Felix Vicq D’Azyr en uno de sus discursos ante la Société Royale de Médecine de París: "Eloge de Sanchez", en Oeuvres de Vicq D'Azyr. Recueillies et publiées avec des notes et un discours sur sa vie et ses ouvrages par Jacques L. Moreau de la Sarthe, t. 4 (París: Imprimerie de Baudouin, 1805).

${ }^{50}$ Sobre la importancia de esta obra en España, véase Pedro Fraile, La otra ciudad del rey. Ciencia de policía y organización urbana en España (Madrid: Celeste Ediciones, 1997), 65. Para el Perú, véanse algunas referencias a su obra en Jean Pierre Clement, El Mercurio Peruano 1790-1795, t. 2 (Madrid: Iberoamericana, 1998), 59-71. 
Mutis la recomienda en 1787 como guía para el plan de estudios de la cátedra de matemáticas en el Colegio Mayor del Rosario ${ }^{51}$.

La primera parte del tomo IX se consagra a la arquitectura civil; ahí Bails expone diversas consideraciones sobre la relación existente entre la construcción de la ciudad y de algunos edificios con la salud pública, con Tissot como autor de primera referencia ${ }^{52}$. Tanto en la obra de Ribeiro como en los apartes del texto de Bails hay una reflexión precisa que constituye el eje articulador: la inquietud arquitectónica y urbanística en relación con la salud pública ${ }^{53}$.

En cuanto a la obra de Ribeiro Sanches, es citada en forma manifiesta por Mutis cuando trata de explicar el problema de los cementerios situados en las iglesias, y cuando muestra la forma de luchar contra ciertos fenómenos epidémicos. Sobre este último caso, en una misiva que data de 1805, Mutis apela a este libro para señalar al Virrey Amar y Borbón la manera más adecuada de limpiar el aire y los objetos contaminados con "el veneno de la viruela". En dicha comunicación, el médico gaditano critica los procederes realizados hasta entonces para llevar a cabo tal purificación, como eran los de quemar todas las ropas y utensilios de las víctimas, o los de picar y revocar las paredes de sus habitaciones, lo que consideraba un costoso sacrificio para las familias; en lugar de esto, propone servirse de los entonces nuevos conocimientos en materia de química para elaborar algunas recetas que habían ya sido experimentadas de manera eficaz en Génova y Andalucía $^{54}$.

La receta aconsejada por Mutis para ser utilizada tanto en las casas de familia como en los hospitales ${ }^{55}$ era de la autoría de Ribeiro Sanches ${ }^{56}$. Mutis elabora también otra receta más simple, cuyos ingredientes eran menos caros y más accesibles para los habitantes de la región, basándose en el mismo texto de Ribeiro;

\footnotetext{
51 Además, ha sido considerado el trabajo matemático de carácter enciclopédico más importante publicado en castellano durante el siglo XVIII. José María López Piñero y otros, eds., Diccionario histórico de la ciencia moderna en España, t. 1 (Madrid: Península, 1983), 92-94. Sobre los destinos de la obra de Bails en el virreinato, véase Luis Carlos Arboleda, "Comentarios sobre las lecturas matemáticas de Mutis", en Historia social de la ciencia en Colombia, t. 2 (Bogotá: Colciencias, 1992).

${ }^{52}$ Benito Bails, Elementos de matemática, t. 9 (Madrid: Imprenta de la Viuda de Joaquín Ibarra, 1796), 123.

${ }^{53}$ La edición del tomo IX que se encuentra en el fondo antiguo de la BNC es la de Bails, Elementos de matemática.

${ }^{54}$ Guillermo Hernández de Alba, comp., Escritos científicos de Don José Celestino Mutis, t. 1 (Bogotá: Kelly, Instituto Colombiano de Cultura Hispánica, 1983), 244.

${ }^{55}$ Constaba de una libra de cada uno de los siguientes componentes: azufre, pino, hojas de tabaco, pimiento seco, cominos, enebro, jengibre, incienso, raíces de aristoloquia redonda y media libra de sal de amoníaco, lo cual se mezclaba y se convertía en polvo. Ibídem.

${ }^{56}$ Ibídem.
} 
de esta forma adapta esta receta para el uso local, aprovechando los elementos más fáciles de encontrar en el medio. Mutis inscribe así, en un contexto diferente, una sencilla y útil práctica de salud, lo cual constituye una muestra de la apropiación de un cierto saber sobre una manera de combatir a enfermedad en la Nueva Granada ${ }^{57}$.

Fue también muy significativa entre el conjunto de lecturas de la élite neogranadina la obra del médico escosés, profesor del Colegio Médico de Edimburgo, William Buchan (1729-1805), Domestic medicine or, a treatise on the prevention and course of diseases by regime and simple medicines, with an appendix, containing a dispensatory for the use of private practitioners (1769). Este libro fue traducido al castellano por Pedro Sinnot y publicado en Madrid en 1785, bajo el título de Medicina doméstica o casera, y tratado completo sobre los medios de conservar la salud, precaver y curar las enfermedades por el régimen y remedios simples:obra tan útil para toda clase de gentes, como fácil la práctica de sus reglas. Otra traducción al castellano, también publicada en 1785 , fue realizada por el historiador y militar Antonio de Alcedo ${ }^{58}$.

Domestic medicine aparece, por ejemplo, como referencia en un artículo que trata sobre una de las dolencias más comunes en la Nueva Granada, el bocio (coto), publicado en el Papel Periódico de Santafé. Cuando el autor del texto pretende explicar las posibles causas de esta enfermedad apela a los estudios de este médico: "El Doctor Guillermo Buchan en su Medicina doméstica (...) se persuade a que semejante causa [cierto tipo de aguas] concurre a producir esta clase de tumores" ${ }^{\text {"59 }}$.

\section{Ver y leer: las plantas medicinales}

¿Qué plantas no habrá en nuestros campos que por solo no saber que son tal o cual, no nos aprovechamos de sus virtudes, y tal vez las compramos por mucho dinero! En nuestro Popayán se vendía en botica el sándalo cetrino por adarmes, hasta que se vio que era el amarillo de peña, de que estamos abundantes ${ }^{60}$.

\footnotetext{
${ }^{57}$ Silva, Las epidemias, 71.

${ }^{58}$ Sobre las diferencias entre las dos traducciones, véase Perdiguero, "Popularizando la ciencia", 164. Esta obra contiene tres partes esenciales: la primera se consagra a las causas de las enfermedades, la segunda se detiene en el estudio de algunas de ellas y la última se dedica a las medicinas que deberían emplearse para tratar cada dolencia.

59 "Reflexiones sobre la enfermedad que vulgarmente se llama coto", Papel Periódico de Santafé de Bogotá (Bogotá) núm. 137, abril de 1794, p. 675.

${ }^{60}$ Francisco José Caldas, Cartas de Caldas (Bogotá: Academia Colombiana de Ciencias Exactas, Físicas y Naturales, 1978), 26.
} 
Los manuales de salud se emplearon también para confrontar, para comparar, para establecer relaciones entre lo observado y lo leído, sobre todo en relación con el estudio de las plantas medicinales locales ${ }^{61}$. En este sentido, se aprecia una actitud que los ilustrados privilegiaban, una aproximación a la realidad que debería ser a la vez metódica, teórica y empírica. Un acercamiento racional fundado en la observación y la experiencia.

La observación consistía en constatar y acumular, a través del testimonio de los sentidos, un conjunto de hechos de la naturaleza. La experiencia era la elaboración racional de las observaciones mediante el establecimiento de relaciones causales válidas y repetidas entre los fenómenos observados ${ }^{62}$. Durante el siglo XVIII, este gusto por la experimentación alcanzó un gran auge. Según Tissot, para poder confiar en las conclusiones derivadas de la experiencia, sería imprescindible multiplicar las observaciones: cuanto mayor fuera su número, más alto sería el grado de certeza de las conclusiones. Siguiendo este sistema no se obtenía nunca una certeza demostrativa absoluta, sino solamente una "certeza moral" o "práctica" que en medicina se consideraba suficiente para afirmar los conocimientos. A este mismo método se hizo también referencia en las declaraciones de intenciones de otras obras publicadas en la época, como el Tratado da saúde da consevaçao dos povos o el Art de se conserver en santé. Lo que se dibuja aquí es una suerte de ida y vuelta, de vaivén entre, por un lado, la lectura del libro, la observación y el análisis de la realidad y, por otro, la experimentación, en este caso, con las plantas medicinales presentes en este territorio.

Por su parte, en este aspecto, es necesario situar las inquietudes del círculo cultural neogranadino en la amplia constelación de intereses metropolitanos en lo relativo a la medicina, la farmacología y la economía; y aunque ello cuestiona el interés y la verdadera pasión científica que animaba la búsqueda de plantas medicinales, las coloca en justo acuerdo con las políticas científicas de la metrópoli, aunque no fueran radicalmente nuevas en el siglo XVIII.

\footnotetext{
${ }^{61}$ En este aparte se tratará solo de las plantas medicinales en relación con los manuales de salud, si bien existen trabajos valiosos sobre este tema, desde otros puntos de vista, en la Nueva Granada, véase Mauricio Nieto Olarte, Remedios para el imperio. Historia natural y apropiación del Nuevo Mundo (Bogotá: Instituto Colombiano de Antropología e Historia, 2000); José Antonio Amaya, "Mutis, apôtre de Linné en Nouvelle-Grenade. Histoire de la botanique dans la viceroyauté espagnole de la Nouvelle-Grenade 1760-1783" (Tesis doctoral, EHESS, París, 1992); Olga Restrepo Forero, "En busca del orden: ciencia y poder en Colombia", en Asclepio (Madrid), 50, núm 2, (1998): 33-75.

62 Ángel González de Pablo, "Sobre la configuración del modelo de pensamiento de la higiene actual: el caso español”, Dynamis. Acta. Hisp. Med. Sci. Illus. (Málaga), 15 (1995): 276.
} 
Desde 1570, Felipe II había asignado a los protomédicos de las Indias la tarea de hacer la relación de las diferentes prácticas médicas del Nuevo Mundo, anotando los árboles, las hierbas o las semillas medicinales que encontraran, para mandarlas a España si eran desconocidas. Sin embargo, el primer proyecto de recolección sistemática de información sobre los conocimientos médicos locales solo comenzó en 1574, año en el cual una Cédula Real ordenó la recopilación y la traducción de las relaciones sobre las prácticas médicas indígenas, que fueron publicadas en 1597 con el título de Instrucción y memorias de la descripción de las Indias que su Majestad mandó hacer para el buen gobierno y ennoblecimiento dellas ${ }^{63}$.

Antes del siglo XVIII, aparecerán, además de estas instrucciones, otras publicaciones sobre plantas medicinales que contribuyeron a crear grandes expectativas sobre las propiedades curativas del mundo vegetal americano. Los autores de estas obras concebían a América como un jardín inagotable de plantas medicinales, muchas de las cuales eran utilizadas eficazmente por los nativos ${ }^{64}$. Este interés se incrementó en las últimas décadas del siglo XVIII, como consecuencia de la ejecución de la política borbónica en ultramar, que buscaba, entre otras cosas, la explotación de las riquezas naturales mediante el control de su producción y comercialización. En este sentido, se propuso la realización de un inventario de los recursos florísticos de las colonias, dando prioridad a los vegetales útiles para la industria, la medicina y el comercio. Este planteamiento se vió reforzado por la incorporación del sistema linneano a la botánica española y por la creación de jardines botánicos, uno de cuyos principales objetivos era convertirlos en centros de investigación, herborización y aclimatación de las plantas de ultramar. Así, la botánica española, adaptada a la ciencia moderna, buscó la renovación de su arsenal farmacéutico ${ }^{65}$.

El deseo de aclimatar las plantas medicinales americanas al suelo español llevó a las autoridades metropolitanas a pedir a Casimiro Gómez Ortega -entonces Director del Jardín Botánico de Madrid- la elaboración de una Instrucción sobre el método más seguro y económico de transportar plantas vivas por mar y tierra a los países distantes (1779). Dicha instruccion debería servir de guía a todas las personas vinculadas a proyectos expedicionarios (y no solamente) en el Nuevo Mundo; en este texto queda confirmada la directriz gubernamental y se pone de manifiesto el interés por la búsqueda de vegetales con virtudes medicinales, con la

\footnotetext{
${ }^{63}$ Nieto, Remedios para el imperio, 139.

${ }^{64}$ Ibídem, 93.

${ }^{65}$ Eduardo Estrella, "Expediciones botánicas", en Carlos III y la ciencia de la Ilustración, eds. Manuel Selles, José Luis Peset y Antonio Lafuente (Madrid: Alianza Universidad, 1988), 331.
} 
ambición de hallar en la "rica botica de la naturaleza americana" los remedios para las enfermedades más frecuentes en Europa ${ }^{66}$.

Este interés farmacológico se concretó en la realización de importantes expediciones botánicas a ultramar. Tales expediciones produjeron un gran inventario, múltiples descripciones y acopios de vegetales y de "materiales exóticos", que deberían ponerse al servicio y fortalecer la frágil economía metropolitana $^{67}$. La Expedición Botánica que se llevó a cabo en la Nueva Granada (1783-1816), por ejemplo, favoreció el conocimiento de múltiples plantas medicinales que formaban parte de la flora neogranadina.

Aquí se aprecia un elemento fundamental para comprender uno de los más importantes efectos del proceso de recepción del pensamiento ilustrado en la Nueva Granada: la transferencia de elementos del imaginario cultural metropolitano a los ideales culturales de la élite ilustrada local. Ello produce una situación compleja que une y homogeneiza a los ilustrados locales en sus intereses y al mismo tiempo los hace partícipes y fervientes adeptos de la política científica de la Corona ${ }^{68}$.

Así pues, los europeos buscaron construir sistemas de clasificación de todos los seres vivos hallados en América, utilizando para ello la analogía con los conocidos en el Viejo Mundo; la actitud de estudio de las plantas locales a partir de su similitud con las plantas presentes en el antiguo continente es clara en Mutis y en el círculo ilustrado neogranadino, como se verá posteriormente.

Este "descubrimiento" de nuevas especies o de las nuevas plantas medicinales debe ser explicado como un proceso de traducción de saberes locales propios de los habitantes de América a la ciencia de la Ilustración europea, es decir, como un proceso que pretende establecer un lenguaje universal a partir del saber local ${ }^{69}$.

En este contexto específico del estudio de las plantas medicinales, la obra de Tissot se encuentra de nuevo en primer plano. El ejemplo del presbítero Andrés Zamora, vecino de la ciudad de Panamá, es significativo. En una de sus cartas a Mutis, este sacerdote se quejaba del poco conocimiento que se tenía en su población de las virtudes medicinales de algunas plantas de la región. En su correspondencia hace

\footnotetext{
${ }^{66}$ A. Gonzalo Bueno y R. Rodríguez Nozal, "Conocimiento científico y poder en la España Ilustrada: hacia la supremacía comercial a través de la botánica medicinal", Antilia. Revista española de historia de las ciencias de la naturaleza y de la tecnología (Madrid) vol. 1 (1995): 3.

${ }^{67}$ Ibídem, 2.

${ }^{68}$ Sobre este proceso, véase en detalle Silva, Los ilustrados, 204 y ss.

${ }^{69}$ Véase la explicación detenida de esta tesis y los casos ilustrativos que estudia Nieto, Remedios.
} 
referencia particular a una planta llamada cicuta, que crecía en los rastrojos y cuyas hojas servirían para curar "los cancros" ${ }^{70}$. El cura pensaba que esta era la misma planta de la cual Tissot trataba en su libro. Según el religioso, el médico suizo refiere cómo, con el extracto de sus hojas, administrado en píldoras o disuelto en agua natural y endulzado con azúcar, se habían "curado varios cancros [sic] y enfermedades de la piel" ${ }^{171}$.

Esta voluntad de comparación aparece también en múltiples ocasiones referida a la quina. En una oportunidad, el cura Blas José de Obregón y Uribe comunica a Mutis que en la región de Panamá había experimentado con todas las clases de quina que producía el reino, pero que la única con efectos rápidos y eficaces para el tratamiento de "las enfermedades de lombrices y de las fiebres tercianas y cuartanas" (paludismo) era la conocida bajo la denominación de praecipu, de lo cual infería que ella era "la selecta de que trata Mr. Fissot [sic] contra estas epidemias" $"$.

El estudio de la quina fue una de las más intensas pasiones de Mutis; de hecho, su única obra completa conocida fue El arcano de la quina (1793), publicada primero por fascículos en el Papel Periódico de Santafé de Bogotá y luego en forma integral en Madrid (1828). Este estudio recoge abundante información sobre las distintas especies de quina y sobre su adecuado uso; ofrece también varias fórmulas medicinales creadas por Mutis. Su intención era la de normalizar la identificación y la clasificación de las especies, sus efectos terapéuticos y sus formas de administración. Sin embargo, el estudio de la quina también fue una de las más importantes actividades de los miembros y colaboradores de la Expedición Botánica y de algunas otras personas del círculo cultural neogranadino ${ }^{73}$.

Otra de las preocupaciones importantes en materia de plantas medicinales que ocupó a este círculo ilustrado fue la búsqueda de vegetales con propiedades antiofídicas, quizá debido a la abundancia de serpientes venenosas existentes en el reino, a la frecuencia con que la mordedura de estos animales se presentaba y a sus consecuencias, generalmente mortales. Debe además tenerse en cuenta que durante el siglo XVIII existió una gran actividad de apertura de fronteras en algunas regiones de la Nueva Granada, como Santander, Antioquia y el Cauca, y ello

\footnotetext{
${ }^{70}$ Hoy se sabe que los entonces llamados cancros son las úlceras de origen sifilítico, a las cuales se les daba este nombre porque producían un dolor intenso como el provocado por el cáncer. Podían localizarse en cualquier parte del cuerpo.

${ }^{71}$ Carta enviada desde Panamá a Mutis, noviembre 1 de 1802 . Hernández de Alba, Archivo epistolar, 4: 289.

${ }_{72}$ Carta dirigida a Mutis desde Yolombó, noviembre 18 de 1804. Ibídem, 83.

${ }^{73}$ Sobre Mutis y la quina, véase: Gonzalo Hernández de Alba, Quinas amargas (Bogotá: Academia Colombiana de Historia, 1994).
} 
pondría de presente cómo tales hechos fueron obstáculos para llevar a cabo el objetivo colonizador.

Hay un episodio significativo que se comentará in extenso, por ser clara evidencia de la inquietud por este tipo de temas en la época y de la creciente valoración de la actitud experimental de este grupo de ilustrados. Existía una práctica curativa tradicional, atribuída a los negros que vivían en las orillas del río Magdalena, según la cual el zumo de las hojas de una planta llamada guaco ${ }^{74}$ servía como "cura" contra la mordedura de serpientes venenosas. A finales del siglo XVIII, varios ilustrados pretendieron llevar a cabo un proceso de validación y de legitimación de este saber ancestral mediante la experimentación con seres humanos ${ }^{75}$. Esa aventura experimental fue llevada a cabo por varios colaboradores de la Expedición Botánica del Nuevo Reino de Granada y por algunos vecinos de la región de Mariquita, especialmente por Pedro Fermín de Vargas ${ }^{76}$ y Francisco Javier Matis ${ }^{77}$.

En una ocasión, Pedro Fermín de Vargas consumió el zumo de las hojas de la planta, sujetándose a la práctica con la cual los negros hacían sus curaciones. La operación se desarrolló de la siguiente manera: Vargas bebió dos cucharadas de

${ }^{74}$ En su Memoria de la primera época sobre insectos, aves, ofidios, plantas y fósiles del Nuevo Reino de Granada, escrita por Mutis poco tiempo después de haber llegado a la Nueva Granada, se refiere al ave llamada guaco cuando trata sobre los gavilanes. Dice que era conocida por su graznido gangoso y que había dado su nombre a un "bejuco contra [la] taya", pues se pensaba que ese animal había "descubierto" las propiedades curativas de la planta contra la mordedura de serpientes. Puede así apreciarse cómo se opera un desplazamiento semántico en que el nombre del ave pasa a ser el de la planta. El ave conocida con el nombre común de guaco (Herpetotheres cachinnan, familia Falconidae) es estrictamente americana y fue descrita por Linneo en 1758.

75 Véase un estudio de esta "aventura" en Adriana María Alzate Echeverri, "Las experiencias de José Celestino Mutis sobre el uso del guaco como antiofídico", Asclepio (Madrid), vol 55, núm 2 (2003): 257-280.

${ }^{76}$ Vargas nació en San Gil (Santander) en 1762. Realizó estudios en el Colegio Mayor de Nuestra Señora del Rosario en Santafé de Bogotá, ocupó el cargo de Oficial Primero de la Secretaría del Virreinato, fue corregidor y juez de residencia de Zipaquirá, estuvo vinculado a la Expedición Botánica desde 1784, donde supervisó el acopio de quina por sugerencia de Mutis. Es uno de los personajes más brillantes de la generación de la Independencia. Sobre Vargas, véase Roberto María Tisnes, Pedro Fermín de Vargas: biografía de un precursor (Bucaramanga: s. e., 1979); Alberto Miramón, Dos vidas no ejemplares: Pedro Fermín de Vargas y Manuel Mallo (Bogotá: Academia Colombiana de Historia, 1962).

77 Francisco Javier Matiz (Guaduas, 1763-1851), se desempeñó como pintor de la Expedición Botánica y fue también maestro en la escuela de dibujo que se estableció allí. Véase Santiago Díaz Piedrahíta, Matís y los dos Mutis: orígenes de la anatomía vegetal y de la sinanterología en América (Bogotá: Academia Colombiana de Ciencias Exactas, Físicas y Naturales, 2000). 
dicho zumo preparado por un negro curandero, luego este último le hizo ocho incisiones (una en cada pie, otra en el índice y en el pulgar de cada mano y las dos últimas en el pecho); cuando la sangre ya empezaba a manar por las heridas, el negro derramó encima de ellas un poco del zumo y luego procedió a frotar cada herida con la hoja.

Después de realizada esta operación, los negros decían que la persona podía considerarse "curada", o sea, en capacidad de tomar cualquier serpiente sin correr peligro por su mordedura. Así lo hizo Vargas inmediatamente. Cogió una serpiente entre sus manos, sin que el reptil experimentase gran irritación. Luego se la pasó a Francisco Javier Matis, quien la agitó de tal manera que el animal terminó mordiéndolo y sacándole un poco de sangre. El negro que los acompañaba, dando muestras de gran serenidad, frotó a Matis con las hojas de la planta, asegurándole que no había peligro. En efecto, nada vino después de esa mordedura, "quedando todos convencidos -dice Mutis- de la bondad del remedio y deseosos de su propagación en beneficio de la humanidad"78.

En un documento que forma parte de su archivo epistolar, Mutis escribe que sería bueno exportar ese vegetal a España y procurar su difusión en el mundo. Propone como método para conducirlo a esas tierras realizar con él un extracto, en forma de píldoras o embotellado. Agrega que tal vez con un auxilio químico podrían hallarse en esta planta otras virtudes recomendables. Conjetura la posibilidad de utilizarla contra las lombrices, pues ellas participarían, de alguna manera, de la naturaleza de las serpientes. Alude también a sus posibles bondades para tratar dolencias estomacales $^{79}$.

Con el deseo de confirmar las virtudes del guaco, Mutis dirige una carta al Virrey Ezpeleta en octubre de 1792, en la que se hace aún más evidente su afán utilitario y su devoción experimental. En dicha comunicación Mutis expone la necesidad de que, de una vez por todas, se defina la utilidad del guaco como antiofídico. Asegura que aún no había sido llevada a cabo una demostración tajante y que, para realizar la experiencia decisiva, era preciso que el gobierno tomara cartas en el asunto. Para obtener tal certeza, Mutis proponía específicamente al virrey que le permitiera emplear dicha planta sobre un reo a muerte ${ }^{80}$.

\footnotetext{
${ }^{78}$ Hernández de Alba, Archivo epistolar, 2: 59.

${ }^{79}$ Ibídem, 61.

${ }^{80}$ En su misiva, Mutis enumera las causas por las cuales dicha experiencia podría haber dado falsos resultados; considera, por ejemplo, que quienes habían participado en la aventura podrían haberse servido de culebras "inocentes" o haberlas privado de su veneno arrancándoles los colmillos o por otros medios. Quizá intervino también la acción de otra planta que la persona "curada" estuviese consumiendo al mismo tiempo que el guaco, sin que por ello fuese posible determinar cuál fue la planta que produjo verdaderamente el efecto. Ibídem, 75 .
} 
De una manera que hoy podría parecer moralmente escandalosa, esta propuesta hace visible una clara exaltación del interés superior de la ciencia y de la experimentación en "beneficio del género humano", caro ideal del hombre ilustrado. Al finalizar su misiva, Mutis deja en manos del virrey esta decisión, agregando que, de todas maneras, le quedaba un aire de satisfacción al haber podido pronunciarse ante él "en obsequio de la humanidad, inspirado sólo en los pensamientos de la utilidad pública" $"$.

En esta situación también se aprecia la actitud de cotejo con las plantas europeas. Para ello, el texto de William Buchan se ofrece como referencia de trabajo. En una parte de su correspondencia relativa a este asunto, Mutis menciona los estudios del médico inglés Tonnent, quien observó en las personas mordidas por la culebra cascabel síntomas semejantes a los de la pleuresía y la pneumonía (dificultad para respirar, tos, esputos de sangre, pulso acelerado, etc.); estas personas se curaban -a juicio del médico inglés- con una preparación de senega. Mutis compara las virtudes de esta planta con las del guaco y refiere una receta con la senega que mencionaba Buchan en su libro Medicina doméstica: "También tenemos nosotros esta misma planta -anota Mutis- y sería bueno que se hiciese, así de una como de otra, la debida exportación a España y se vulgarizase tan prodigiosa medicina en el mundo" $"$.

Según el conocido escrito de Jorge Tadeo Lozano, Memoria sobre las serpientes (1808), las virtudes del guaco seguían sin confirmarse. En esta obra, Lozano se dedica a describir "el ejército de remedios" que habían sido empleados en las tierras neogranadinas para curar los efectos de la mordedura de serpientes venenosas; al final de esta relación, trata sobre el guaco y anota: "este antídoto celebrado es el único del que se afirma, que no solo cura la mordedura actual, sino que a los que diariamente beben su zumo o su cocimiento los preserva de la picadura, o en caso de recibirla no les hace el menor daño". Lozano mencionaba

\footnotetext{
${ }^{81}$ El virrey dirigió esta petición a la Real Audiencia de Santafé para que allí se dictaminase lo que se debía hacer. Tiempo después, el fiscal de su majestad en lo civil y lo criminal dictó una resolución donde consideraba que lo principal era la conservación y el cuidado de la especie humana; por ello, expresa que no veía ninguna "repugnancia legal" que impidiera el hecho y accede a la propuesta. Nunca se ha sabido, con certeza, si tal prueba se llevó a cabo.

${ }^{82}$ Hernández de Alba, Archivo epistolar, 2: 61-62. Remítase, asimismo, a Ibídem, 4: 200. Esta semejanza sugerida por Mutis es acertada. Tiempo después, se confirmarán las virtudes del guaco (Mikania guaco) como antiofídico, expectorante, antiasmático y broncodilatador, análogas a las de la senega (Polygale de virginie). Véase sobre este tema B. M. Ruppelt, E. F. Pereira, L. C. Goncalves, N. A. Pereira, "Pharmacological screening of plants recommended by folkmedicine as anti-snake venom. Analgesic and anti-inflamatory activities", Mem. Ins. Oswaldo Cruz (Sao Paulo), 86, suppl. 2 (1991): 203-205.
} 
que en la Nueva Granada esa certeza se basaba en repetidas observaciones, aunque él conocía un caso en el que la planta no había tenido efecto alguno ${ }^{83}$. Por ello afirmaba que deberían hacerse más experimentos con este vegetal para averiguar definitivamente la manera como obraba ${ }^{84}$.

Por otro lado, la apelación a esta obra de Buchan aparece de nuevo, siempre en esta búsqueda de plantas nativas con virtudes antiofídicas, en relación con las supuestas propiedades de un vegetal estudiado por el médico escocés: la escabiosa o persicaria ${ }^{85}$. Por su parte, el librito de recetas de Madame Fouquet fue también objeto de tales confrontaciones. De ello da cuenta el naturalista Fray Diego García $^{86}$ en carta enviada a Mutis:

Luego que hice la remesa del Malambo he visto con más reflexión lo que dice Madame Fouquet sobre el Colpachi [sic] y me inclino a que esta corteza de Malambo es el verdadero Colpachi y no el laurel de la corteza blanca a quien ningún amargo se lo encuentra; lo cierto es que el Malambo no solo es vermífugo, sino febrífugo, pues las gentes pobres, que no tienen ni conocen la quina, con él se destierran las calenturas y lo mismo he observado en los mediquines de estas partes que la suministran como la quina a falta de esta ${ }^{87}$.

${ }^{83}$ Jorge Tadeo Lozano, "Memoria sobre las serpientes y plan de observaciones para aclarar la historia natural de las que habitan el Nuevo Reino de Granada, y para cerciorarse de los verdaderos remedios capaces de favorecer a los que han sido mordidos por las venenosas" (1808), Semanario del Nuevo Reino de Granada (Bogotá) t. 1, 1942, 115-132.

${ }^{84}$ Ibídem, 122.

${ }^{85}$ Véase el Papel Periódico de Santafé de Bogotá (Bogotá), t. 4, núm 134, marzo de 1794, p. 649 .

${ }^{86}$ Fray Diego García (Cartagena 1745-Mompox 1794). Aunque es un personaje poco conocido, desempeñó una labor importante en la Real Expedición Botánica del Nuevo Reino de Granada (1783-1816), donde fue el primero de sus comisionados y laboró como adjunto durante casi cinco años. Su trabajo, iniciado en 1783, se centró en la región del alto valle del río Magdalena; allí realizó importantes observaciones de campo y recolectó múltiples materiales con destino a los gabinetes de historia natural. Por otro lado, llevó a cabo minuciosos estudios de zoología. En sus estudios de carácter botánico se destacan sus investigaciones sobre la coca, la quina y varias especies de interés económico, así como novedosos trabajos sobre otras plantas medicinales. Santiago Díaz Piedrahíta, "Fray Diego García y los orígenes de la zoología sistemática en Colombia”, Colombia, Ciencia y Tecnología (Bogotá) vol. 19, núm 1 (enero-marzo, 2001): 3-11. Sobre García, véase también Luis Carlos Mantilla R. y Santiago Díaz Piedrahíta, Fray Diego García, su vida y su obra científica en la Expedición Botánica (Bogotá: Academia Colombiana de Ciencias Exactas Físicas y Naturales, Instituto Colombiano de Cultura Hispánica, 1992).

${ }^{87}$ Carta enviada a Mutis desde Santa Marta, 18 junio de 1787. Hernández de Alba, Archivo epistolar, 3: 374. Sobre la presencia de esta autora en las bibliotecas venezolanas, véase Ildefonso Leal, Libros y bibliotecas en la Venezuela colonial, Biblioteca de la Academia Nacional de la Historia, Caracas, 1978, p. 307. 
Se conoció como copalchi (croton febrífugo) la corteza de un árbol del mismo nombre, que poseía supuestamente virtudes febrífugas. Son célebres los estudios realizados con este vegetal por los expedicionarios novohispanos M. Sessé y J. M. Mociño, presentados ante la Real Academia de Medicina de Madrid ${ }^{88}$. En otra ocasión, la misma planta aparece de nuevo en relación con esta autora, según se desprende de la nota que Don Manuel Castillo dirige a Mutis a finales del siglo XVIII: "Noticia del uso que se ha hecho de una cáscara nombrada corpicho [sic] y efectos que de él han resultado". Allí, Castillo señala:

Parece que esta [planta] es la misma de que hace mención Madame Fouquet en su colección de remedios, en el tomo que trata de los externos, dándole el nombre de colpachi. Dice haberse descubierto nuevamente en las Indias Occidentales, y hace una enumeración bien exacta de las virtudes que en ella se han observado; no contrayendo precisamente su aplicación a las enfermedades exteriores, sino también a las internas.

Y anota, asimismo, que se sabía de la existencia de esta planta en Neiva, Ibagué y en otras tierras calientes ${ }^{89}$.

\section{Recetas para los pobres y automedicación}

Los habitantes de esta ciudad tienen una cultura mucho mayor de lo que pudiera esperarse, pero mucho menor de lo que ellos se imaginan. Aquí todos recetan, porque han leído a Tissot ${ }^{90}$

A. von Humboldt

Este comentario de Humboldt, realizado durante su estadía en Popayán (noviembre 1801), no solo muestra la "popularidad" de Tissot en el virreinato, sino que pone en evidencia los usos que se le dieron a una de sus obras en la Nueva Granada: el Avis, que, como los otros manuales de salud, sirvió a los ilustrados y a las "personas caritativas" para recetar a los pobres y también de apoyo a prácticas de automedicación.

\footnotetext{
${ }^{88}$ El estudio sobre este vegetal se titula: "Virtudes de la corteza del palo nombrado copalchi remitidas de Veracruz con fecha de 16 de enro de 1802". Raúl Rodríguez Nozal y Antonio González Bueno, "Real Academia Médica Matritense y Expediciones Botánicas", Dynamis. Acta Hisp. Med. Sci. Hist. Illus. (Málaga), 15 (1995): 380-381.

${ }^{89}$ ARJBM, "Expediciones científicas", Expedición de José Celestino Mutis, signatura III, 5, $1,41$.

${ }^{90}$ Carta de Humboldt a Mutis. Popayán, noviembre de 1801. Hernández de Alba, Archivo epistolar, 4: 11.
} 
Fuera del recurso al médico, al que pocos tenían acceso en la Colonia, las gentes acudían a varios métodos de curación, entre los cuales se encontraban algunos de tipo ritual practicados en el seno de la comunidad negra e indígena o de la familia. Es necesario recordar que, a diferencia de lo que ocurre en la actualidad cuando se va al médico para ser curado, en aquella época las ambiciones del "tratamiento" eran más modestas, se recurría al médico o a ciertos métodos terapéuticos sólo con la esperanza de aliviar el dolor, de permitir al enfermo retomar su trabajo o, simplemente, de aportarle una suerte de "confort psicológico". De ahí que sea muy difícil estrablecer juicios sobre el éxito o el fracaso de las estrategias terapéuticas del pasado ${ }^{91}$.

El campo de la automedicación y de la receta a los pobres constituye una importante dimensión del mundo de las prácticas terapéuticas. Sin embargo, el gran obstáculo para su estudio se encuentra en la ausencia casi total de testimonios escritos que revelen tales prácticas. Se conservan, por fortuna, algunos fragmentos de correspondencias que sugieren elementos que permiten pensar en la realidad de estas prácticas y que sirven de intermediarias entre el libro y la tradición oral.

\section{Prescripciones para los necesitados}

En ocasiones, algunas personas con ciertos conocimientos médicos se servían de este tipo de libros para recetar a los pobres; así, una "palabra mediadora" se hacía lectora para acudir al llamado de los enfermos analfabetas o iletrados ${ }^{92}$. Ante la escasez de médicos, las gentes, pobres y no tan pobres, acudían a algunos miembros de esta élite cultural, a algunos curas o a personas caritativas en busca de ayuda. Los curas cumplían labores no solo de salvación y cuidado del alma, sino de sanación del cuerpo; en este contexto, debe mencionarse igulamente la labor de algunos "aficionados" a la medicina que, sin ser reconocidos como curanderos, ejercían labores de consulta y en ocasiones de experimentación médica con plantas nativas, empleándolas para sanar personas cercanas. En las regiones neogranadinas, los poseedores de los manuales de salud eran, desde luego, personas que sabían leer, ante quienes las gentes acudían esporádicamente para interrogarlos sobre sus males.

La importancia de los curas, en este sentido, está relacionada tanto con la falta de médicos como con la permanencia de la medicina caritativa (dimensión religiosa de la enfermedad), pues si bien el médico empieza a ganar un lugar más importante en esta época, la figura del sacerdote como agente de salud seguirá vigente durante

91 Roy Porter, "Les stratégies thérapeutiques", en Histoire de la pensée médicale en Occident, t. 2 (París: Le Seuil, 1996), 199.

92 Roger Chartier y Daniel Roche, "Les pratiques urbaines de l'imprimé", en Histoire de l’Edition Française (París: Fayard, 1990), 546. 
mucho tiempo. A título heurístico, es posible pensar que, para este fin, fueron de utilidad varios de los libros que aquí se han mencionado, sobre todo aquellos que proponen una mirada global al saber médico en sentido enciclopédico.

En una de las cartas citadas anteriormente se aprecia que algunas personas sin formación médica asumían la curación de sus vecinos, amigos o familiares. En la correspondencia del mencionado Don Manuel Castillo con Mutis, sobre el colpachi, el primero narra las virtudes de esta planta y dice que es "empleada tradicionalmente en Tunja". Allí, un mercader, Don José Manuel Mota, la había utilizado para curar varias de las dolencias de los pobladores. Castillo refiere que, en abril de 1793, se había servido de esta planta, cocida en aguardiente, para lavar y curar a una mujer que padecía de un cancro en la palma de una mano, del "cual sanó dentro de muy breve tiempo" 93 .

El mercader narra que también había usado esta planta para sanar a un religioso de San Francisco que se hallaba imposibilitado por el crecimiento de una carnosidad en el dedo pulgar "que se persuadía también [de que] fuese cancro". La gravedad de su afección era tal que un médico había ya dictaminado la necesidad de cortar el dedo. Pero un día antes de sufrir esta operación, el religioso quiso hacer la experiencia con tal cáscara, persuadido por el mismo Mota, quien, en efecto, se la aplicó en forma similar que a la mujer (con quien ya había hecho prueba de la eficacia del remedio), y "logró que tuviere un conocido alivio, que aumentándose le condujo a la mejoría y entero restablecimiento, haciéndole caer toda aquella carnosidad"94.

Entre los miembros de esta élite cultural neogranadina que poseían conocimientos médicos pueden citarse Jerónimo Torres ${ }^{95}$, Antonio Nariño y Pedro Fermín de Vargas. En cuanto al primero, sus cartas muestran la constante demanda de libros

\footnotetext{
93 Nota que Don Manuel del Castillo dirige a Mutis a fines del siglo XVIII. ARJBM, "Expediciones centíficas", signatura III, 5, 1, 41.

94 Don José Manuel Mota refiere también el caso de una mujer que tenía una mano paralizada a la cual le dispensó los baños con la planta mencionada, lo que "le restituyó su flexibilidad". Relata luego el sinnúmero de experiencias favorables que había obtenido con la planta cocida en agua, contra las caries, contra las fluxiones de la cara, para detener la sangre de las heridas y sanarlas, contra las picaduras de culebras y para fortalecer el estómago. ARJBM, "Expediciones científicas", signatura III, 5, 1, 41.

95 Jerónimo Torres (Popayán 1771-Bogotá 1839) inició sus estudios en el Seminario de Popayán y luego se tituló como abogado en Quito. Partidario de la independencia, fue ayudante de milicias, juez y fiscal civil, criminal y de hacienda de la Junta Republicana de Gobierno constituida en Popayán. Establecida la República, se desempeñó como senador, consejero de Estado y contador general de Hacienda, entre otros cargos. Era hermano de Camilo Torres. Fuera de su formación jurídica, era un personaje con amplios saberes en otras áreas y con una gran capacidad de liderazgo. José María Vergara y Vergara, Historia de la literatura en la Nueva Granada (Bogotá: Echeverría Hnos., 1867), 286-287.
} 
médicos a su hermano Camilo, que habitaba en Santafé $^{96}$, y sus reiterados intercambios de comentarios de obras, diagnósticos, opiniones y muestras de plantas medicinales. Sus conocimientos médicos le permitían diferenciar los signos de algunas enfermedades o criticar los diagnósticos establecidos por médicos de profesión; en su correspondencia, Jerónimo Torres deplora las insuficiencias del saber médico de la época y denuncia sus defectos, como los pocos elementos de juicio que se tenían para realizar la clasificación y el establecimiento del diagnóstico de las enfermedades. Se muestra partidario de la elaboración de descripciones precisas de las enfermedades y de sus síntomas.

La comunicación que desde Popayán dirige a su hermano Camilo en octubre de 1807 es elocuente en este sentido. Allí Jerónimo refuta el diagnóstico que había sido dado al médico Mariano Grijalba ${ }^{97}$, quien tenía una "rarísima" afectación del pecho "acompañada de gran disnea" y que, según el parecer de Jerónimo, no era asma ni pleuresía ni una enfermedad cardíaca, sino una semiparálisis de los músculos intercostales; así, en la carta se lee:

... [esta es una] afección desconocida para el mismo Dr. Mariano y también para mí en nuestra práctica, sin que el empírico arte de curar, llamado por ironía ciencia médica -en el estado lamentable de atraso en que se halla aún en la culta Europa y por ende en la bárbara América española- nos suministre alguna regla fija o por lo menos la más tenue luz para formar diagnósticos diferenciales ${ }^{98}$.

En ocasiones, Jerónimo recibía incluso consultas médicas por correspondencia. En una carta que su hermano Ignacio remite desde San Juan, le pregunta: “... qué sera bueno para que le venga la menstruación a una negra que tiene 21 años y no conoce las primeras (...) Ella está constantemente consumida de moco, que parece ética (...) y le dan unas calenturas" ${ }^{\prime 9}$.

Jerónimo Torres desempeñó, asimismo, una importante actividad salubrista ante las epidemias de viruela que azotaron su región, con una actitud abierta ante los

\footnotetext{
${ }^{96}$ Véase, por ejemplo, la carta de mayo de 1808. Archivo General de la Nación, Academia Colombiana de Historia, Archivo Camilo Torres (AGN, ACH, ACT) caja 5, carpeta 8.

${ }^{97}$ Mariano Grijalba estudió medicina en la Universidad de San Marcos de Lima, vivió en Popayán como Prebenda de Racionero, motivo por el cual, a pesar de ser médico, se mantenía apartado del ejercicio profesional. Pilar Gardeta Sabater, Sebastián José López Ruiz (1741-1832) (Málaga: Universidad de Málaga, 1996), 22.

${ }_{98}$ Carta dirigida a su hermano Camilo Torres desde Popayán, el 20 de octubre de 1807. AGN, ACH, ACT, caja 14, carpeta 28, fol. 11r. Véase también, en este sentido, la carta que desde Quito envía a su padre (18 agosto 1778) sobre un diagnóstico que juzga equivocado, en Ibídem, carpeta 27, fol. 74r. Resaltado de la autora.

${ }^{99}$ Carta remitida desde San Juan por Ignacio Torres, quien pregunta por su hermano en Popayán, septiembre 27 de 1806. AGN, ACH, ACT, caja 7, carpeta 14, fol. 6r.
} 
nuevos comportamientos de salud y convencido de que una población sana y abundante era el principio de la prosperidad ${ }^{100}$.

Por su parte, Antonio Nariño (1765-1823) ${ }^{101}$ conoció, sin duda, varias de las obras de las que se trata aquí, como lo sugiere, una vez más, la correspondencia de Mutis. En una ocasión que el médico gaditano había solicitado a Don Ignacio Roel (su apoderado en Santafé) la obra de Buchan Medicina doméstica, este le responde que Nariño se la había llevado, así que sería necesario que Mutis recurriera a él para pedírsela prestada, ya que Roel no tenía amistad con Don Antonio ${ }^{102}$.

Algunos refieren que Nariño recetaba a los pobres "con un acierto tal que en su familia conservaban durante largos años las fórmulas y recetas con que había curado graves enfermedades"103; con alguna frecuencia se asesoraba de médicos de formación, como Louis de Rioux y Antonio Froes ${ }^{104}$. Algunos consideraban que "sabía de medicina como cualquier médico"105.

Por otro lado, Pedro Fermín de Vargas tenía un verdadero interés y saber médicos, como se manifiesta en sus diversos escritos ${ }^{106}$. Tomaba a su cargo, por ejemplo, la curación de sus criados, como se desprende de la carta que desde Zipaquirá (1791) dirige a Salvador (posiblemente, el mayordomo de la Expedición Botánica), solicitándole nueces moscadas y quina anaranjada para curar las fiebres tercianas que uno de sus criados padecía desde hacía varios días ${ }^{107}$. Participó en la importante tarea de experimentación que tenía como objeto verificar las virtudes antiofídicas del arbusto llamado guaco, como se ha anotado, y fue autor de una

\footnotetext{
${ }^{100}$ Silva, Las epidemias.

101 "Estando aún muy joven se vió abocado [sic] a manejar los negocios de su familia a la muerte de su padre, e incluyó la importación de libros en sus negocios. Entre sus clientes estaban Pedro Fermín de Vargas y Jerónimo Torres; varios de los médicos del virreinato fueron también 'figuras prominentes' en sus listas de venta o préstamo de libros: Mutis, Miguel de Isla y Froes, entre otros". Margarita Garrido, Antonio Nariño (Bogotá: Panamericana, 1999), 12, 14, 21.

${ }^{102}$ Hernández de Alba, Archivo epistolar, 4: 201.

${ }^{103}$ Soledad Acosta de Samper, Biografia del General Antonio Nariño (Pasto: Imprenta del Departamento, 1910), 11.

${ }^{104}$ Eduardo Ruiz Martínez, La librería de Nariño, 64.

105 Enrique Santos Molano, Antonio Nariño, vol. 1 (Bogotá: Instituto Colombiano de Cultura, 1972), 34.

${ }^{106}$ Lo testimonia otra de sus obras: "Plan de las constituciones que se presentan al excelentísimo señor Virrey del Reino para el Hospital Real de San Pedro de la parroquia de Zipaquirá"; para un estudio de este plan, véase Adriana María Alzate Echeverri, "Devociones políticas y oratoria salubrista: sobre un plan de reforma hospitalaria en la Nueva Granada (1790)", Historia Critica (Bogotá), 23 (2002): 51-72.

${ }^{107}$ ARJBM, "Expediciones científicas", signatura III, 1, 3, 879.
} 
memoria sobre el tema. Al parecer, se dedicó a ejercer la medicina en Jamaica ${ }^{108}$ y posteriormente en La Habana, con cierto éxito profesional, bajo el nombre de Fermín Sarmiento ${ }^{109}$. En su correspondencia, Antonio Nariño refería que Vargas pensaba viajar a Francia y seguir practicando allí como médico en el Hospital General de París ${ }^{110}$.

\section{La automedicación}

Otra utilización de este tipo de libros tiene relación con las prácticas de automedicación, la cual no está exclusivamente determinada por un contexto de penuria de médicos o por insuficiencia de recursos económicos para pagarlos, pues estos no son los únicos motivos que conducen a las gentes a empreder su propia curación o a preservarse de la enfermedad. Las prácticas de automedicación se relacionan con dos concepciones: la del naturalismo médico y la de la medicina sin médico. En la primera, se supone que Dios o la Naturaleza han dispuesto en el cuerpo los remedios suficientes para la curación de todas las enfermedades. Por el contrario, la medicina sin médico, que se desarrolló sobre todo a partir del siglo XVI, se sirvió de los manuales de salud para guiar o ayudar al enfermo en el diagnóstico y para proponerle una suerte de autoterapia ${ }^{111}$.

Una antigua tradición filosófica y médica presenta la automedicación como una actitud y una acción positiva y no como un reflejo de supervivencia vinculado con una situación de pobreza o reducido a la esfera de la cultura popular ${ }^{112}$. En la Nueva Granada, esta práctica tampoco era nueva a fines del siglo XVIII, como se desprende de un documento judicial de 1562, perteneciente al proceso que sigue el médico Francisco Díaz contra varios de sus clientes por la remuneración de sus servicios: "Se ha visto que los más vecinos y otras personas, por experiencias que han tenido, tienen conocidas sus complexiones y se saben sangrar y purgar con cosas que por experiencia se ha visto ser provechosas, por lo cual algunos enfermos no han tenido necesidad del dicho médico y ha sido Dios servido de darles salud" ${ }^{\prime 113}$.

\footnotetext{
${ }^{108}$ Roberto María Tisnes J., Un precursor, don Pedro Fermín de Vargas (Bogotá: Kelly, 1969), 40, 42.

109 Alberto Miramon, Dos vidas no ejemplares: Pedro Fermín de Vargas, Manuel Mallo (Bogotá: Publicaciones Editoriales Bogotá, 1962), 32.

${ }^{110}$ Tisnes, Un precursor, 40, 42.

${ }^{111}$ Bernard Andrieu, "Médecin de soi-même", en Michel Foucault et la médecine. Lectures et usages (París: Editions Kimé, 2001), 90.

${ }^{112}$ Carl Havelange, Figures de la guérison (XVIII-XIX siècles). Une histoire sociale et culturelle des professions médicales au pays de Liège (París: Edition "Les Belles Lettres", 1990), 157.

${ }^{113}$ AGN, Juicios civiles de Cundinamarca, t. 46, fol. 517.
} 
Pero las personas caritativas y algunos médicos, curas o ilustrados no eran los únicos en recetar a los pobres o en predicar las virtudes de la automedicación; en el contexto familiar, en la vida cotidiana, cada persona disponía de ciertos remedios que le permitían luchar contra sus dolencias. Así, administrarse remedios, darlos a los miembros de la familia o, más generalmente, aconsejar a vecinos y amigos eran prácticas habituales. Algunos recomendaban el uso de manuales en determinadas situaciones, en ausencia del médico, como hace Mutis, por ejemplo, ante las epidemias de viruela:

... hará muy bien de consultar al médico quien pueda y donde no haya este recurso, se podrán tomar algunas luces en el capítulo de viruelas del sabio Tissot en su libro Aviso al pueblo, obra superior a todas las de esta clase y que no puede leerse sin el debido reconocimiento a su célebre autor por su amor a la humanidad ${ }^{114}$.

El tema del médico de sí mismo se basa, en parte, en conceptos tradicionales de higiene, que pueden ser traducidos en preceptos fáciles de recordar, de comprender y de seguir. Este era, igualmente, uno de los objetivos de los manuales de medicina doméstica o popular, en los cuales los lectores eran invitados a buscar medios económicos y eficaces para curarse y tratarse a sí mismos ${ }^{115}$. Estos consejos de higiene tienen una importancia decisiva porque constituyen los fundamentos mismos de la medicina sin médico, cuya acción se pretende tanto preventiva como curativa $^{116}$.

Por razones económicas y culturales, para el enfermo no siempre es indispensable un mediador, llámese médico, curandero o santo. Ellos intervienen generalmente después de varias tentativas infructuosas del enfermo por sanarse a sí mismo. La automedicación es siempre la primera reacción para combatir la enfermedad, el primer recurso terapéutico empleado. Para curarse no es necesario apelar sistemáticamente al médico, que no es el único depositario del saber; si escucha la naturaleza, cada persona puede aplicar las recetas médicas que le han sido transmitidas.

Para comprender las herramientas terapéuticas que este tipo de manuales proponía a sus lectores, es necesario considerar que en aquel entonces no existía una diferencia clara entre los métodos empleados para conservar la buena salud y los necesarios para recobrarla. Esta medicina aconsejaba un modo de vida que tenía en cuenta el aire que se respiraba, las normas dietéticas, las excreciones, el sueño,

\footnotetext{
${ }^{114}$ Guillermo Hernández de Alba, "Método general para curar las viruelas", en Escritos científicos, t. 1 (Bogotá: Instituto Colombiano de Cultura Hispánica, 1983), 198. Resaltado de la autora.

${ }^{115}$ Evelyne Aziza-Shuster, Le médecin de soi-même (París: PUF, 1972), 103.

${ }^{116}$ Havelange, Figures de la guérison, 156.
} 
el ejercicio físico y el control de las pasiones. Estos factores, llamados "no naturales", eran esenciales para evitar las enfermedades o para curarlas.

El pensamiento médico de entonces concebía la salud como la permanencia del equilibrio y la armonía naturales y utilizaba de manera preventiva y terapéutica diferentes procedimientos naturales, como la dieta, la sangría y los baños ${ }^{117}$. Las prescripciones que se consagran en estas obras son simplísimas: reposo, dieta, bebidas abundantes, alimentos simples, lavativas ligeras, purgación, aireación de la pieza del enfermo, cambio frecuente de su ropa de cama y, sobre todo, paciencia; se percibe así un afán pedagógico que se funda a la vez en una concepción pesimista y negativa del pueblo, crédulo, impaciente, ignorante, y en un optimismo fundamental sobre la posibilidad de su perfectibilidad física y moral que le permitiría vencer su ingenuidad, su ignorancia y su impaciencia, y en darle los medios para remediar en parte los problemas causados por la ausencia de médicos o por la "desordenada" vida de los individuos.

En síntesis, los manuales de salud más leídos en la Nueva Granada a finales del siglo XVIII y principios del XIX, al igual que en España y en algunos países de Europa, fueron Avis au peuple sur sa santé; Domestic Medicine, y Tratado da conservaçao da saude dos povos. Ellos constituyeron unas de las más importantes obras de referencia en el proceso de apropiación de los saberes relacionadas con la salud pública en este virreinato. Este tipo de libros contribuyó al conocimiento de ciertas plantas autóctonas y de sus virtudes medicinales, a partir de la comparación con las que existían y se utilizaban en Europa, volviéndose así un elemento importante en la construcción de un saber sobre los recursos naturales propios de este territorio.

Por otra parte, se ha podido apreciar uno de los aspectos más importantes relativos a la recepción de las ideas de la salud pública en la Nueva Granada: el papel de los sacerdotes como intermediarios culturales. A veces también eran ellos quienes incitaban o sugerían a las autoridades la importancia para las poblaciones de observar algunas medidas de salud. Asimismo, estos manuales de salud estaban destinados en particular a los sacerdotes. Hay un ámbito en el cual estuvieron muy presentes, como se ha apreciado a lo largo del presente artículo, y es el de la exploración de los recursos naturales. Se constató la presencia de un conjunto de curas herboristas que recogen plantas, realizan estudios y experiencias sobre sus posibles virtudes medicinales y escriben, confrontan y comunican sus resultados por correspondencia, formando así parte de una red naciente de intercambios

\footnotetext{
${ }^{117}$ Estas medidas, recomendadas por los médicos de la Antigüedad, provenían de grandes autores islámicos y habían sido transmitidas al Occidente latino durante la Edad Media a través de la Escuela de Salerno. Porter, "Les stratégies thérapeutiques", 206.
} 
científicos. Los sacerdotes actuaron también como difusores de ciertas prácticas de salud en las zonas rurales, donde muchos debían ejercer su magisterio. Indudablemente, el tema de los sacerdotes como agentes de salud en esta época y en este territorio deberá estudiarse a fondo en futuros trabajos.

Por otro lado, la exploración de las correspondencias y de los escritos de los ilustrados neogranadinos refleja varios aspectos importantes de la Ilustración local. Se percibe una imagen aún borrosa, pero significativa, que requerirá de otros estudios acerca del lugar que ocupa la correspondencia médica como espacio de desarrollo de consideraciones sobre un tema médico o terapéutico determinado. Puede entreverse que la correspondencia desempeñó un papel de soporte entre los diferentes niveles de elaboración de un saber, en este caso, el relacionado con las plantas y sus virtudes medicinales. En ellos se percibe también un "método" de adquisición del conocimiento, desarrollado a partir de la lectura, la observación, el análisis de la realidad local y la experimentación, dinámica de aprendizaje que se hace muy evidente en relación con la utilización terapéutica de ciertos vegetales.

Durante el siglo XVIII, sostener una correspondencia era una actividad banal para la mayor parte de las personas pertenecientes a esta élite. Las cartas comunicaban anécdotas y rumores de la familia y amigos; pero la actividad epistolar también era útil para la vida intelectual. Entre los médicos y aficionados a la medicina existió en la Nueva Granada una constante correspondencia con sus pares, en forma semejante a lo que sucedía desde el siglo XVII, cuando los médicos de Europa se servían del correo para anunciarse mutuamente sus progresos, descubrimientos y solicitar la cooperación o la crítica.

\section{Bibliografía}

\section{Fuentes primarias}

Archivo del Real Jardín Botánico de Madrid, Madrid, España.

Archivo General de la Nación, Bogotá, Colombia.

Biblioteca Nacional de Colombia, Bogotá, Colombia.

\section{Periódicos}

Correo curioso, erudito, económico y mercantil de Santafé de Bogotá (Santafé de Bogotá), 4 de agosto de 1801.

Papel Periódico de Santafé de Bogotá (Bogotá, Colombia) 1793- 1795. 


\section{Fuentes secundarias}

Acosta de Samper, Soledad. Biografia del General Antonio Nariño. Pasto: Imprenta del Departamento, 1910.

Alcaide González, Rafael. "Las publicaciones sobre higienismo en España durante el período 1736-1939. Un estudio bibliométrico". Scripta Nova (Barcelona), 37 (abril 1999).

Alzate Echeverri, Adriana María. Los oficios médicos del sabio. Contribución al estudio del pensamiento higienista de José Celestino Mutis. Medellín: Universidad de Antioquia, 1999.

- "Devociones políticas y oratoria salubrista: sobre un plan de reforma hospitalaria en la Nueva Granada (1790)". Historia Crítica (Bogotá), 23 (2002): 51-72.

. "Las experiencias de José Celestino Mutis sobre el uso del guaco como antiofídico". Asclepio (Madrid), 55, núm. 2 (2003): 257-280.

Amaya, José Antonio. "Una flora para el Nueva Reino. Mutis, sus colaboradores y la botánica madrileña (1791-1808)". En Culturas científicas y saberes locales, ed. Diana Obregón. Bogotá: Universidad Nacional de Colombia, CES, 2000.

. "Mutis, apôtre de Linné en Nouvelle-Grenade. Histoire de la botanique dans la viceroyauté espagnole de la Nouvelle-Grenade 1760-1783". Tesis doctoral, EHESS, París, 1992.

Andrieu, Bernard. "Médecin de soi-même". En Michel Foucault et la médecine. Lectures et usages. París: Ediciones Kimé, 2001.

Arango Jaramillo, Mario, Augusto Peinado y Juan Santa María. Comunicaciones y correos en la historia de Colombia y Antioquia. Bogotá: Editorial Gente Nueva, 1996.

Arboleda, Luis Carlos. "Comentarios sobre las lecturas matemáticas de Mutis". En Historia social de la ciencia en Colombia. T. 2. Bogotá: Colciencias, 1992.

Aziza-Shuster, Evelyne. Le médecin de soi-même. París: PUF, 1972. 
Bails, Benito. Elementos de matemática. T. 9. Madrid: Imprenta de la Viuda de Joaquín Ibarra, 1796.

Bruhier, Jean-Jacques. Dissertation sur l'incertitude des signes de la mort et abus des enterrements et embauments précipités. París: Bure, 1749.

Bueno, A. Gonzalo y R. Rodríguez Nozal. "Conocimiento científico y poder en la España ilustrada: hacia la supremacía comercial a través de la botánica medicinal". En Antilia. Revista española de historia de las ciencias de la naturaleza y de la tecnología (Madrid), 1 (1995).

Caldas, Francisco José. Cartas de Caldas. Bogotá: Academia Colombiana de Ciencias Exactas, Físicas y Naturales, 1978.

. "Sobre el influjo del clima en los seres organizados". En Semanario del Nuevo Reino de Granada. T. 1. Bogotá: Biblioteca Popular de Cultura Colombiana, 1942.

Chartier Roger y Daniel Roche. "Les pratiques urbaines de l'imprimé" En Histoire de l'Edition Française. París: Fayard, 1990.

Clement, Jean-Pierre. El Mercurio Peruano, 1790-1795. T. 2. Antología. Madrid: Vervuert-Frankfurt, Iberoamericana, 1998.

Caycedo, Bernardo, D’Elhuyar y el siglo XVIII. Bogotá: Kelly, 1971.

Daremberg, Charles Víctor. La médecine, histoire et doctrines. 2 ed. París: Didier, 1855.

Demerson, Paula de. "Muertes aparentes y socorros administrados a los ahogados y asfixiados en las postrimerías del siglo XVIII". Asclepio (Madrid, CSIC), 53, núm. 2 (2001): 45-68.

Díaz Piedrahíta, Santiago. Matís y los dos Mutis: orígenes de la anatomía vegetal y de la sinanterología en América. Bogotá: Academia Colombiana de Ciencias Exactas, Físicas y Naturales, 2000.

- "Fray Diego García y los orígenes de la zoología sistemática en Colombia". Colombia, Ciencia y Tecnología (Bogotá), 19, núm. 1 (eneromarzo, 2001): 3-11. 
Doria, José Luis. "Antonio Ribeiro Sanches: a portuguese doctor in $18^{\text {th }}$ century Europe". Vesalius, Acta Internationalis Historiae Medicinae (Bruselas), 7, núm. 1 (junio 2001): 27-35.

Estrella, Eduardo. "Expediciones botánicas". En Carlos III y la ciencia de la Ilustración, eds. Manuel Selles, José Luis Peset y Antonio Lafuente. Madrid: Alianza Universidad, 1988.

Fajardo, José del Rey. La biblioteca colonial de la Universidad Javeriana de Bogotá. Caracas: Pontificia Universidad Javeriana, Universidad Católica del Táchira, s. f.

Farge, Arlette. "Se conserver en santé au XVIII siècle. D'après les guides, dictionnaires ou arts de se conserver en santé". En Le corps, la santé, la maladie. Travaux et Recherches du Groupe d'Histoire Moderne et Contemporaine du CNRS, 18-26. París: CNRS, 1979.

Fraile, Pedro. La otra ciudad del rey. Ciencia de policía y organización urbana en España. Madrid: Celeste Ediciones, 1997.

Fere, Guyot de. "Gardane, Joseph-Jacques". En Nouvelle biographie générale. T. 19. París: MM. Firmin Didot Frères, 1858.

Feyel, Gilles. "Periódicos". En Diccionario histórico de la Ilustración, eds. Vincenzo Ferrone y Daniel Roche. Madrid: Alianza, 1988.

Foucault, Michel. "La politique de santé au XVIII siècle". En Michel Foucault. Dits et Ecrits. T. 2. París: Gallimard, 2001.

Fouquet, Madame-Marie. Recueil de receptes, où est expliquée la manière de guérir à peu de frais toutes sortes de maux. Le tout a été expérimenté par les charitables soins de Mme. Fouquet. Lyon: Certe, 1676.

Frias Núñez, Marcelo. Enfermedad y sociedad en la crisis colonial del Antiguo Régimen. Nueva Granada en el tránsito del siglo XVIII al XIX: las epidemias de viruelas. Madrid: CSIC, 1992.

Gardane, Jacques-Joseph. Catéchisme sur les morts apparentes dites asphyxies ou instruction sur les manières de combattre les différentes espèces de morts apparentes. París: Valade, 1771.

Gardeta Sabater, Pilar. Sebastián José López Ruiz (1741-1832). Málaga: Universidad de Málaga, 1996. 
Garrido, Margarita. Antonio Nariño. Bogotá: Panamericana, 1999.

Guerra, François-Xavier. Modernidad e independencias. Madrid: Mapfre, 1992.

González de Pablo, Ángel. "Sobre la configuración del modelo de pensamiento de la higiene actual: el caso español". Dynamis. Acta Hisp. Med. Sci. Hist. Illus. (Málaga), 15 (1995): 267-299.

Gredilla, Federico. José Celestino Mutis. Bogotá: Plaza y Janés, 1982.

Havelange, Carl. Figures de la guérison (XVIII-XIX siècles). Une histoire sociale et culturelle des professions médicales au pays de Liège. París: Les Belles Lettres, 1990.

Hernández de Alba, Gonzalo. Quinas amargas. Bogotá: Academia Colombiana de Historia, 1994.

Hernández de Alba, Guillermo, comp. Archivo epistolar del sabio naturalista José Celestino Mutis. T. 2. Bogotá: Kelly, Instituto Colombiano de Cultura Hispánica, 1975.

, comp. Escritos científicos de Don José Celestino Mutis. T. 1. Bogotá: Kelly, Instituto Colombiano de Cultura Hispánica, 1983.

"Método general para curar las viruelas". En Escritos cientificos. T. 1. Bogotá: Instituto Colombiano de Cultura Hispánica, 1983.

Ibáñez, Pedro María. Crónicas de Bogotá. T. 1. Bogotá: Biblioteca Cultural de Cultura Colombiana, 1951.

Infantes, Víctor, François Lopez y Jean-François Borrel. Historia de la edición y de la lectura en España (1472-1914). Madrid: Fundación Germán Sánchez Ruiz Pérez, 2003.

Jouanna, Jacques y Caroline Magdelaine. "Présentation". En L'art de la médecine, Hippocrate. París: GF Flammarion, 1999.

Keel, Othmar. L'avènement de la médecine clinique moderne en Europe, 17501815. Politiques, institutions et savoirs. Montréal: Les Presses Universitaires de Montréal, Gerg Editeur, 2001. 
Langet, Mireille y Claudine Luu. Médecine et chirurgie des pauvres. París: Privat, 1984.

Lastres, Juan B. La medicina en el virreinato. Vol. 2. Historia de la medicina peruana. Lima: Imprenta Santa María, 1951.

Leal, Ildefonso. Libros y bibliotecas en la Venezuela colonial. Caracas: Biblioteca de la Academia Nacional de la Historia, 1978.

Lebrun, François. Se soigner autrefois. Médecins, saints et sorciers aux XVII et XVIII siècles. París: Points-Seuil, 1995.

López Piñero, José María y otros, eds. Diccionario histórico de la ciencia moderna en España. T. 1. Madrid: Península, 1983.

Louis, Antoine. Lettres sur la certitude des signes de la mort, ou l'on rassure les citoyens de la crainte d'être enterrés vivants. París: Chez Michel Vambert, 1752.

Lozano, Jorge Tadeo. "Memoria sobre las serpientes y plan de observaciones para aclarar la historia natural de las que habitan el Nuevo Reino de Granada, y para cerciorarse de los verdaderos remedios capaces de favorecer a los que han sido mordidos por las venenosas" (1808). En Semanario del Nuevo Reino de Granada. T. 1: 115-132. Bogotá: Biblioteca Popular de Cultura Colombiana, 1942.

Mantilla R., Luis Carlos y Santiago Díaz Piedrahíta. Fray Diego García, su vida y su obra científica en la Expedición Botánica. Bogotá: Academia Colombiana de Ciencias Exactas Físicas y Naturales, Instituto Colombiano de Cultura Hispánica, 1992.

Martínez Zulaica, Antonio. La medicina en el siglo XVIII en el Nuevo Reino de Granada. Tunja: Universidad Pedagógica y Tecnológica de Colombia, 1972.

Milanesi, Claudio. Mort apparente, mort imparfaite. Médecine et mentalités au XVIII siècle. París: Payot, 1991.

Miramón, Alberto. Dos vidas no ejemplares: Pedro Fermín de Vargas y Manuel Mallo. Bogotá: Academia Colombiana de Historia, 1962. 
Nieto Olarte, Mauricio. Remedios para el imperio. Historia natural y apropiación del Nuevo Mundo. Bogotá: Instituto Colombiano de Antropología e Historia, 2000.

Peligry, Christian. "Le marché espagnol". En Histoire de l'édition française. Le livre triomphant (1660-1830), dir. Roger Chartier y H. Martín, 481-492. París: Fayard, 1990.

Perdiguero Gil, Enrique. "Los tratados de medicina doméstica en la España de la Ilustración". Tesis doctoral, Universidad de Alicante, 1990.

. "The popularization of medicine during the Spanish Enlightenment". En The Popularization of Medecine 1650-1850, ed. Roy Porter. LondresNueva York: Routledge, 1992.

. "Popularizando la ciencia: el caso de la medicina doméstica en la España de la Ilustración". En La Ilustración y las ciencias. Para una historia de la objetividad. Valencia: Universitat de Valencia, 2003.

Porter, Roy. "Les stratégies thérapeutiques". En Histoire de la pensée médicale en Occident. T. 2. París: Le Seuil, 1996.

Restrepo Forero, Olga. "En busca del orden: ciencia y poder en Colombia". Asclepio (Madrid), 50, núm. 2, (1998): 33-75.

Riera, Juan. Capitulos de la medicina española ilustrada. Libros, cirujanos, epidemias y comercio de quina. Valladolid: Universidad de Valladolid, 1992.

Rodríguez, Ana Luz. Cofradías, capellanias, epidemias y funerales. Bogotá: Banco de la República, 1999.

Rodríguez Nozal, Raúl y Antonio González Bueno. "Real Academia Médica Matritense y Expediciones Botánicas". Dynamis. Acta Hisp. Med. Sci. Hist. Illus. (Málaga), 15 (1995): 380-381.

Roche, Daniel. La France des Lumières. París: Fayard, 1993.

Rosen, George. "El mercantilismo y la política para la salud en Francia". En De la policía médica a la medicina social. México: Siglo XXI, 1985.

Ruíz Martínez, Eduardo. La librería de Nariño y los Derechos del Hombre. Bogotá: Planeta, 1990. 
Ruppelt, B. M.; E. F. Pereira; L. C. Goncalves, y N. A. Pereira. "Pharmacological screening of plants recommended by folkmedicine as anti-snake venom. Analgesic and anti-inflamatory activities". Mem. Ins. Oswaldo Cruz (Sao Paulo), 86, suppl. 2 (1991): 203-205.

Santos Molano, Enrique. Antonio Nariño. Vol. 1. Bogotá: Instituto Colombiano de Cultura, 1972.

Sgard, Jean. "La multiplication des périodiques". En Histoire de l'édition française. Le livre triomphant (1660-1830), dir. Roger Chartier y $\mathrm{H}$. Martín. París: Fayard, 1990.

Silva, Renán. Las epidemias de la viruela de 1782 y 1802 en la Nueva Granada. Cali: Universidad del Valle, 1992.

- "Prácticas de lectura, ámbitos privados y formación de un espacio público moderno. Nueva Granada a finales del Antiguo Régimen”. En Los espacios públicos en Iberoamérica. Ambigüedades y problemas. Siglos XVIII-XIX, eds. François-Xavier Guerra y Annick Lemperiere. México: Fondo de Cultura Económica, 1998.

. Los ilustrados de Nueva Granada 1760-1808. Medellín: Fondo Editorial Universidad EAFIT, 2002.

. Universidad y sociedad en el Nuevo Reino de Granada. Contribución a un análisis histórico de la formación intelectual de la sociedad colombiana. Bogotá: Banco de la República, 1993.

Sue, Jean Joseph. Dictionnaire portatif de santé: dans lequel tout le monde peut prendre une connaissance suffisante de toutes les maladies, des différents signes qui les caractérisent chacune en particulier, des moyens les plus surs pour s'en préserver, ou des remèdes les plus efficaces pour se guérir. 6 ed. revue et corr. París: Chez Josep Barbou, 1777.

Teysseire, Daniel. "Aux origines de la médecine sociale et de la politique de la santé publique: l'Avis au peuple sur sa santé de Tissot”. Mots. Les langages du politique (Paris), 26 (1991).

Teysseire, Daniel y Corine Verry-Jouvet. "Présentation". En Avis au peuple sur sa santé Samuel Tissot. París: Chez P. Fr. Didot (1782); París: Quai Voltaire Histoire, 1993. 
Tisnes, Roberto María. Pedro Fermín de Vargas: biografia de un precursor. Bucaramanga: s. e., 1979.

Un precursor, don Pedro Fermín de Vargas. 40, 42. Bogotá: Kelly, 1969.

Unanue, J. H. "Decadencia y restauración del Perú. Oración inaugural que, para la estrena y abertura [sic] del anfiteatro anatómico, dijo en la Real Universidad de San Marcos el día 21 de noviembre de 1792". El Mercurio Peruano (Peru), 218-222 (3, 7, 10, 14 y 17 de febrero de 1793).

Vicq D’Azyr, Felix. “Eloge de Sánchez”. En Oeuvres de Vicq D’Azyr. Recueillies et publiées avec des notes et un discours sur sa vie et ses ouvrages par Jacques L. Moreau de la Sarthe. T. 4. París: Imprimerie de Baudouin, 1805.

Vergara y Vergara, José María. Historia de la literatura en la Nueva Granada. Bogotá: Echeverría Hnos., 1867.

Fecha de recepción: 15 de noviembre de 2004.

Fecha de aceptación: 23 de agosto de 2005. 